\title{
Science, Reason, Knowledge, and Wisdom: A Critique of Specialism
}

\author{
Nicholas Maxwell University College, London
}

Published in Inquiry, vol. 23, 1980, pp. 19-81.

In this paper I argue for a kind of intellectual inquiry which has, as its basic aim, to help all of us to resolve rationally the most important problems that we encounter in our lives, problems that arise as we seek to discover and achieve that which is of value in life. Rational problem-solving involves articulating our problems, proposing and criticizing possible solutions. It also involves breaking problems up into subordinate problems, creating a tradition of specialized problem-solving - specialized scientific, academic inquiry, in other words. It is vital, however, that specialized academic problem-solving be subordinated to discussion of our more fundamental problems of living. At present specialized academic inquiry is dissociated from problems of living - the sin of specialism, which I criticize.

I

In this paper I discuss two rival views about the nature of intellectual inquiry. I call these two views fundamentalism and specialism. I shall argue that at present the whole institutional structure of scientific, academic inquiry, by and large, presupposes specialism. Of the two views under consideration it is, however, fundamentalism, and not specialism, which provides us with a rational conception of intellectual inquiry. Failure to put fundamentalism into practice has profoundly damaging con-sequences for science and scholarship, and indeed for life, for our whole modern world. Ideally intellectual inquiry ought to help us to tackle rationally those problems of living which we encounter in seeking to discover and achieve that which is of value in life. Intellectual inquiry ought, in other words, to devote reason to the enhancement of wisdom (wisdom being defined here as the capacity to discover and achieve that which is of value in life, for oneself and others - wisdom thus including knowledge and understanding). In fact, at present, scientific, academic inquiry gives priority to the achievement of knowledge only, rather than to the achievement of wisdom. It is essentially the general adoption of specialism which is responsible for the persistence of this highly undesirable state of affairs.

II

According to fundamentalism, in the end the whole point of intellectual inquiry is to help us to improve our answers to four fundamental questions, namely:

1. What kind of world is this?

2. How do we fit into the world and how did we come to be?

3. What is of most value in life and how is it to be achieved?

4. How can we help develop a better human world? ${ }^{1}$

In particular, according to fundamentalism, it is a basic task of intellectual inquiry to help us to tackle these four fundamental problems in a rational fashion. Rational problem-solving is understood here to involve, at the very least, putting into practice the two heuristic rules:

a. Articulate, and seek to improve the articulation of, the problem to be solved;

b. Propose and critically assess possible solutions. ${ }^{2}$

There is of course more to rational problem-solving than this. ${ }^{3}$ But these two rules are understood by fundamentalism to constitute the nub of rationality.

Thus, according to fundamentalism, the central and fundamental task of intellectual inquiry is to improve the articulation of the above four problems, and to propose and critically assess possible solutions to them. All other intellectual activity is subservient to this.

A basic idea of fundamentalism is that ideally it is we ourselves who answer the above four questions, as we live. The proper task of reason, thought, intellectual inquiry is to help us to arrive at answers that we really do wish to give 
to these questions, rather than to determine the answers for us. Intellectual inquiry is our servant, not our master. It is not in itself any kind of authority or oracle.

Two further extremely important, elementary heuristic rules of rational problem-solving are:

c. Break up the basic problem to be solved into subordinate, specialized, easier-to-solve problems.

d. Interconnect attempts to solve basic and specialized problems, so that the one may influence and be influenced by the other.

According to fundamentalism, an immense amount of intellectual activity arises, quite properly, as a result of putting these two heuristic rules into practice. That is, in order to improve our answers to our four basic problems we create a vast network of sub-problems and preliminary problems-the specialized, technical problems of science and scholarship. A great deal of intellectual activity consists in seeking to solve these limited, technical problems of specialized scientific, academic disciplines. It is however of supreme importance according to fundamentalism - that we do not lose our way within this network, this maze, of sub-problems. If intellectual inquiry is to be rational, it is essential that intellectual priority be given to the four fundamental problems, and to the tasks of proposing and critically assessing possible solutions to them. In order to tackle specialized problems in a rational fashion, in short, it is essential to tackle such problems as sub-problems of the four fundamental problems. Specialized scientists and scholars, in other words, in order to be rational, must also be philosophers or generalists, concerned in their specialized work to help us solve our fundamental problems.

Figure 1 gives an indication of the way in which some current specialized academic disciplines may be conceived, in fundamentalist terms, as being designed to help us solve the above four basic problems. As the diagram indicates, it is essential for the intellectual integrity and rationality of intellectual inquiry as a whole that there be a constant two-way flow of information between specialized problem-solving and fundamental problem-solving.

Two minor adjustments may be made to the doctrine of fundamentalism as just outlined. In the first place it may be argued that philosophy ought not to be conceived as yet another specialized discipline concerned to solve its own special problems. Rather, philosophy needs to be conceived as that part of the whole intellectual enterprise which seeks to articulate fundamental problems, propose and criticize possible solutions to these problems. Philosophy, according to this conception, constantly gives rise to new specialized problems, and is itself profoundly influenced by our success and failure in seeking to solve specialized problems. It is in just this sense that almost all the great philosophers of the past have contributed to 'philosophy': Plato, Aristotle, Descartes, Bacon, Hobbes, Locke, Spinoza, Leibniz, Hume, Kant. Mill, Comte, Marx, Rousseau, Nietzsche, Mach, Russell - to name a few. It is vital, however, according to this viewpoint, that philosophy is not treated as a specialized, professional discipline, the exclusive preserve of the expert. The whole rationale of intellectual inquiry is to promote fundamental rational problem-solving as widely as possible, as an integral part of life. Rendering this the exclusive task of professional philosophers sabotages utterly the whole raison d'etre of intellectual inquiry. This nonspecialized, fundamentalist conception of philosophy is perhaps above all to be found upheld by the thinkers of the Enlightenment - for whom critical philosophy was the basic instrument of human enlightenment. ${ }^{4}$

Strictly, of course, formulating fundamentalism in terms of this Enlightenment conception of philosophy requires us to modify Figure 1, in that 'philosophy' ceases altogether to be any kind of specialized academic discipline existing alongside other disciplines, and becomes instead identical to all thought about fundamental problems, ideally pursued rationally as an integral part of life. Formulating fundamentalism in this way, however, is unfortunately liable to lead to misunderstandings. Academic philosophers will object to the disappearance of specialized philosophy, not realizing that there must always be an important place in academic inquiry for those concerned with fundamental problems and concerned to promote open, critical discussion of fundamental problems. Everyone else will object to the idea that philosophy should monopolize concern with fundamental problems, 'philosophy' being misunderstood here to mean 'academic philosophy' rather than being understood to be simply all our personal and public thinking about our fundamental problems. The essential tenet of fundamentalism after all is that all inquiry, personal, social, and academic, ought to be organized along fundamentalist lines. Whether or not thought about fundamental problems is called 'philosophy', and whether or not academic philosophy continues to exist as a specialized discipline, are matters of minor importance. In order to avoid misunderstandings concerning these minor matters, I leave Figure 1 unmodified. (The diagram is, in fact, a modified version of the original diagram, one that appears in my Cutting God in Half - And Putting the Pieces Together Again.) 


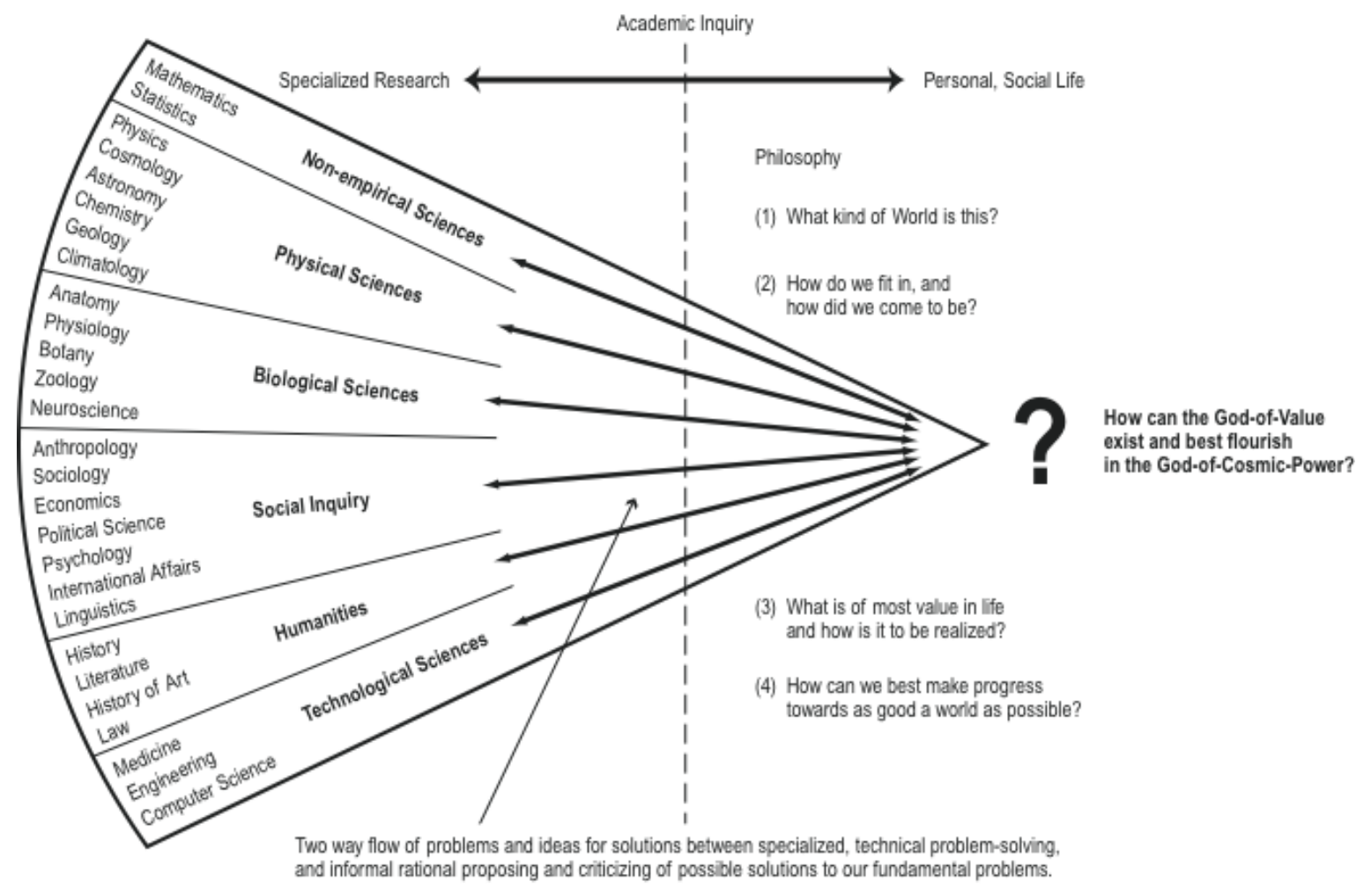

Diagram 1 Wisdom-Inquiry Helping the God-of-Value to Flourish 
The second qualification that may be made to the above viewpoint amounts to this. It is quite wrong - it may be argued - to suggest that the enterprise of seeking to improve our answers to the above four fundamental questions is somehow exclusively the concern of intellectual inquiry. Literature, theatre, music, art, religion can all be interpreted as being concerned to illuminate our responses to these basic questions - especially the last two questions. Our whole culture can, in other words, be conceived of in fundamentalist terms as being designed, ideally, to help us to discover and create that which is of most value in life. In engaging in our work, in social and political activity, we should, ideally - it may be argued - be seeking to develop improved answers in practice to the last two questions, in one way or another. Indeed, in our whole way of life -our way of being on this earth - we give implicitly our actual answers to such questions, whether we are aware of this or not. And in so far as we seek to improve our lives, we seek to improve the actual answers that we give to these questions, in the fabric of our actions. Fundamentalism, in short, needs to be conceived as a philosophy of life, a social philosophy, a philosophy of culture: fundamentalism interpreted as a philosophy of intellectual inquiry is simply a fragment of all this.

Fundamentalism, as just characterized, may seem at first sight to be a somewhat autocratic, doctrinaire position, in that it seems to determine for us what our problems are and how they should be conceived. For this reason, it may at first sight seem unacceptable. For do not our problems -even our 'fundamental' problems - change, quite legitimately, from circumstance to circumstance, from person to person, from culture to culture? Can we really ever know for certain what our fundamental problems are. how they should be conceived? ${ }^{5}$

It will I hope become clear, as the argument unfolds, that my basic purpose in this essay is to depict and argue for - a kind of intellectual inquiry specifically designed to offer us maximum help with discovering for ourselves, whoever we may be, what our own unique problems of living are, how we are to conceive of them, and how we are to set about resolving them. My claim is that intellectual inquiry, so designed, is fundamentalism. It is intellectual inquiry so designed that it has the kind of intellectualinstitutional structure depicted in the diagram above, according to which problems and their discussion are, as it were, hierarchically organized, with four vague, general, fundamental problems at the top, a maze of specific, restricted, precise, specialized problems at the bottom, and in between a continuous range of problems, more and less specific, inter-connecting the top and the bottom by means of the relationship: 'Problem $P_{1}$ is more fundamental than problem $P_{2}$ ' or, equivalently, 'Problem $\mathrm{P}_{2}$ is subordinate to problem $\mathrm{P}_{1}$ '. A few universal, fundamental problems are needed so that we do not get lost in the maze of restricted, specialized problem-solving. These fundamental problems must be formulated informally, imprecisely, without restricting specific presuppositions, just so that all people everywhere, in all societies, cultures, and circumstances, can in principle interpret their own more or less specific, basic problems as specific versions or interpretations of the four fundamental problems, as formulated above. Only this can ensure that no one is excluded a priori from entering into rational inquiry by their own specific circumstances, view of the world, philosophy of life. In addition, we need discussion of more precise, restricted problems so that we can make progress with solving our problems, as a result of putting into practice the third and fourth of the above four rules of rational problem-solving, (b) and (c).

Fundamentalism needs to be implicit in the way in which our own personal thinking and problemsolving is organized, so that we may have the best opportunity to understand and learn from others, even from those who think very differently from ourselves - learning from others being essential for the development of our own capacity to recognize and solve our own problems. ${ }^{5}$ Fundamentalism needs to be built into education, into the intellectual-institutional structure of scientific, academic inquiry, and generally, into our whole social, political, economic, and cultural order, on a world-wide basis, so that learning, understanding and cooperation between people is given every opportunity to flourish.

There is nothing autocratic or doctrinaire in what I am advocating here, just because fundamentalism amounts to a kind of intellectual inquiry, a way of thinking or problem-solving which, when put into practice, gives us our maximum chances of discovering for ourselves what our own unique problems are and how they are to be solved, enabling us, ideally, to exploit for this purpose the very best thinking or problem-solving that humanity has to offer. The autocratic and doctrinaire, the dogmatic, arise to the extent that we fail to put fundamentalism into practice.

Fundamentalist intellectual inquiry can thus incorporate all possible conceptions of the world, all religious views, all philosophies of life, in all possible social and cultural milieux - all possible ways of conceiving of life's problems and how they should be tackled. There is just one proviso: all these diverse 
views and values, in being plugged into fundamentalist inquiry, as it were, must take note of the following basic points: many ways of conceiving of the world, life and its problems, exist and are possible; whoever we may be, our view as to what sort of world this is, and what is of most value in life, is guesswork; we have much to learn from others - especially by taking the achievements and failures, the views, values, and arguments of others seriously, by ourselves engaging, with others, in fundamentalist inquiry, as we live. Sincere attention to the lives, views and values of others is desirable and ought to be held to be desirable - within all viewpoints and value-systems, since this is absolutely essential for mutual understanding in the world, mutual learning, mutual cooperation, peace, friendship, and love. Much of the real richness in life comes from the good things that go on between people; and for these good things to happen, sincere attention to the lives, views, and values of others - fundamentalism built into the pattern of our lives, the structure of society - is essential.

Fundamentalism takes into account the point, stressed especially by Popper in The Open Society and its Enemies, ${ }^{7}$ that social, cultural pluralism or diversity is essential for the development of reason and science - the development of what Popper has called critical rationalism. I shall even argue, somewhat analogously to Popper, that rational inquiry can be understood as developing as a result of our departure from tribal life - from the human compactness and unity of tribal life. In sharp disagreement with Popper, however, I wish to argue that such things as mutual cooperation, mutual learning, understanding, and communication can only flourish within social and cultural diversity if some kind of common unity can be discovered within this diversity. We must be able to agree at some level about what sort of world this is, and what is desirable and of value. Engaging in cooperative intellectual inquiry - the very act of participating in rational discussion - presupposes that it is at least possible to discover or create, at some level, common purposes and assumptions, an agreed framework, an agreed outlook on life and the world. This agreement must, however, accommodate equably the existing differences. It is in order to do justice to this requirement of unity in diversity - essential for cooperative rational discussion and inquiry that fundamentalism postulates or stipulates the above kind of hierarchical ordering of problems and their attempted resolution. The hierarchical structure of fundamentalist inquiry is precisely what we need if we are to discover or create, as readily as possible, just, equable agreement within disagreement, unity within diversity. Agreement can be sought at the fundamental level: disagreement and doubt can then be rationally explored at less fundamental levels, wherever it arises.

In his best epistemological, social, and political thought Popper is centrally concerned to attack authoritarianism, the dogmatic attitude. In The Open Society and its Enemies this concern takes the form of a mighty onslaught upon those major figures in the history of Western thought who, in Popper's view, have failed to come to terms with the strains of civilization - the strain of living in an open, pluralistic society - and, as a result, have given way to romantic longings for the cohesion of the closed society, the tribal way of life. It is this longing, this potent false nostalgia for a golden past, which Popper argues has led even some of the greatest minds, with the best of intentions, to become the enemies of the open society, the enemies of democracy, reason and pluralism, and as a result, tragically, actually helping totalitarianism and fascism to grow, with all the consequent appalling human suffering of our history.

Popper's diagnosis is of fundamental importance. However, in the midst of his ferocious determination to establish once and for all the intellectual disreputability and appalling potential human destructiveness of views which value the tribal way of life, Popper neglects to consider the possibility that there is indeed much to value, potentially, in the cohesive-ness of the tribal way of life which humanity - science, reason, and civilization - cannot do without. ${ }^{8}$ It is just this possibility that is affirmed here. I shall argue that our departure from the human compactness and unity of tribal life does indeed involve serious loss. Mere pluralism is not enough. It is essential that we develop a common unified view of the world and ourselves through cultural and social diversity if there is to be mutual learning, understanding, and cooperation through diversity - minimal requirements for reason and for civilization. Only fundamentalism can do justice to these apparently conflicting requirements of unity and diversity. In our emergence from tribal life into the modern world a basic task confronting us is to create and develop unity within diversity: only by putting fundamentalism into practice can we achieve this in a just, equable, genuinely rational and humane way. Popper's ideal of the 'Open Society' needs to be replaced by the ideal advocated in this essay of the 'Fundamental Society'. It is precisely our failure to establish fundamentalism on a world-wide basis that is responsible for so much suffering in modern times, and which indeed at present threatens us all. (I refer here to our present world-wide incapacity to cope with fundamental problems posed by such things as the population explosion, the 
continuing rapid depletion of vital, finite natural resources, widespread poverty and malnutrition in the third world, the balance of terror which persistently threatens to engulf us all in the nuclear holocaust. A fundamentalist world order is, almost by definition, a world order capable of recognizing its fundamental problems and, where possible, developing and putting into practice, in a cooperative fashion, just, humane, effective solutions.)

Popper's failure to recognize the vital need to create or develop a version of tribal unity within the diversity, complexity, and sheer immensity of the modern world, in order to preserve and develop reason, mutual cooperation, humanity and civilization, is intimately connected with his analogous failure to recognize the vital role that fundamental unifying assumptions play in science, and in academic inquiry in general. Scientific, academic inquiry has basic presuppositions about what sort of world this is and what is important or of value in social life, built into its whole intellectual-institutional structure, built into the priorities for research, built into its implicit methodology. According to fundamentalism, these basic presuppositions need to be explicitly articulated and scrutinized - thus creating a tradition of discussion of presupposed solutions to fundamental problems - if scientific, academic inquiry is to be genuinely rational and rigorous, of maximum human value and use. Only by putting fundamentalism into scientific, academic practice can we do justice to -and develop - the inherent rationality, the intellectually progressive character, and the human value, of the best of scientific, academic work and thought. As we shall see below, Popper fails to characterize adequately the rationality and progressive character of science - in that, for example, he fails to solve the problem of induction -ju st because he fails to do justice to the need for fundamental metaphysical and evaluative assumptions persisting through scientific revolutions, scientific diversity.

The Open Society and its Enemies fails to characterize a genuinely rational society: The Logic of Scientific Discovery fails to characterize a genuinely rational science: both failures are by-products of Popper's basic failure to articulate and advocate the hierarchical structure of fundamentalism, so essential for genuinely rational, cooperative problem-solving and inquiry in life as well as thought.

Having argued that we need to recognize, quite generally, that our thinking goes on in the world, presupposing a view of the world and a view of what is of value in life, I am of course eager to acknowledge that my advocacy of fundamentalism in this essay is intimately bound up with a view of what sort of world this is and what is of value in life - a broad, general, fundamental answer to the fundamental questions (1) and (3) above. As to the material universe I hold a view not too dissimilar from the over-all conception of the world implicit in much of modern science - a view of the world which does justice to the probable truth of Einstein's remark that 'all our science, measured against reality, is primitive and childlike - and yet it is [one of] the most precious thing[s] we have'. ${ }^{9}$

I recognize, of course, the intellectual legitimacy of conceptions of the world - such as animistic and religious views - very different from that of modern science: fundamentalist inquiry acknowledges such rivals, and retreats to a more modest $\bullet$ common sense' view of the world, designed to be indifferent between these rival, explanatorily fundamental views, so that there may be a common, agreed base in terms of which the merits of the rival explanatorily fundamental views may be discussed. (Fundamentalism recognizes, in other words, that, in certain contexts, and for certain purposes, the epistemologically fundamental may differ from what is presumed to be ontologically and explanatorily fundamental.)

As to that which is of value, I hold that all that is of value in existence has to do with life, and especially, for us, with human life. Enjoyment in living; curiosity and wonder; perceptive awareness, understanding and appreciation of significant and beautiful aspects of the world; kindness, laughter, honesty, friendship, love, intimacy, cooperative creative work, personal responsibility, happiness, fulfilment: these are the kind of things that are of value. For each one of us, this short life is our only opportunity to discover, experience, take part in, life of value; all too many people in the modern world - especially the third world - lack this opportunity. We need to do all we can to change things so that all people everywhere have the opportunity to realize what is of most value in life. Value in the world has much to do with the diversity of life, the unique particularity of each individual life. A uniform world would be a world denuded of value. It is of the essence of value - it is essentially desirable and of value - that there be multiplicity and variety, amongst people, amongst ways of life, amongst societies and cultures. However, if this desirable variety is to flourish in this one crowded world, it is essential that we discover how to cooperate, to learn from and understand each other, in the midst of this variety. And there is a further point. As I have remarked above, much of what is of value in life comes directly from good things that go on between people -mutual understanding and appreciation, sharing, intimacy, 
cooperative creative work. Such interpersonal or social things, of value in themselves, only become possible in a world full of variety if there is cooperation, communication, learning, and understanding amidst variety. Variety is only enriching in so far as there is understanding and learning between people amidst variety. It is to help facilitate all this that I advocate fundamentalism. Fundamentalism is put forward as a conception of learning and problem-solving designed, above all, to help us resolve more adequately the third and fourth of the above fundamental problems.

Amongst other things, fundamentalism amounts to a reply to social and cultural relativism. Like relativism, fundamentalism acknowledges the existence and value of social, cultural, and intellectual diversity. Unlike relativism, fundamentalism recognizes that we all live in a common world in which we all have a real value, and that we all need to learn from one another so that mutual understanding and cooperation may flourish - so that what is of value in all our lives, potentially and actually, may flourish. The existence of a multiplicity of cultures need not prevent us from recognizing our common humanity, our common value, since it is at least possible for this multiplicity to be interlaced with and unified by a common acceptance of fundamentalism.

Adoption of fundamentalism is especially important for societies and cultures in the third world. For in learning from the industrially advanced West - in acquiring the science, technology, and industry of the West -there is always the grave danger that the indigenous culture and social order will simply be annihilated, ${ }^{10}$ as opposed to being helped to develop and flourish. A third-world society can only avoid this danger by articulating, at a fundamental level, basic presuppositions, values, and problems of the society, so that it becomes possible to discover how to develop these presuppositions and values, solve these problems, in the new social and cultural circumstances made possible by the importation of Western ideas and techniques. Only in this way can such a society employ these ideas and techniques discriminatingly, for its own best purposes, instead of becoming a hollow imitation of the Western way of life. In addition, of course, the industrially advanced West has a special responsibility, in its interactions with the third world, to construe its own social and cultural order in fundamentalist terms. Only cooperative fundamentalism can enable a mutually desirable kind of learning to go on in both directions.

Analogous considerations arise in connection with education. The most profound, instinctive, and passionate fundamentalist thinkers are of course very young children - since all children must, as a practical necessity, arrive at working answers to the four fundamental questions in order to become human. If education is to develop, and not annihilate, instinctively fundamentalist childish thought, then education must itself be organized along fundamentalist lines. ${ }^{11}$ Only those teachers who learn from their pupils really educate.

To sum up: fundamentalist inquiry does justice to the Socratic and Kantian idea that reason forms a basis for the unity of mankind, in such a way as to encourage the flourishing of desirable kinds of diversity within this unity; it might be called 'the tribal discussion of humanity'. Fundamentalism cannot, of course, of itself vanquish tyranny, exploitation, manipulation, war, terrorism, crime. Fundamentalism does, however, hold out the hope that if it is actively promoted in our personal, social, intellectual, economic, and political lives wherever possible, then the spirit and practice of mutual cooperation between people may gradually grow, thus enabling us gradually to dismantle those social and cultural arrangements which tend to breed misunderstanding and mistrust, manipulation, and exploitation, the use and abuse of power, the dreadful spiral of threat, counter-threat, and violence.

So much for my preliminary exposition of fundamentalism: I turn now to a consideration of the rival doctrine of specialism.

For most scientists, scholars and educationalists today, specialism is a much more familiar doctrine than fundamentalism: my exposition of specialism can therefore be much briefer. Specialism, unlike fundamentalism, is almost exclusively a view of professional, expert, scientific, academic inquiry even though this view, being embodied in so much present-day scientific, academic practice, has farreaching consequences for all our personal, social lives. In complete contrast to fundamentalism, specialism insists that only the specialized, technical problems of the various academic disciplines deserve serious intellectual attention. In order to be capable of serious scientific or scholarly treatment, in other words, a problem must satisfy certain conditions. It must be capable of being given an agreed, precise formulation. The problem must have an objective character, in that experts agree as to how the problem is to be formulated. The nature of the problem must not depend on such subjective, personal, or idiosyncratic matters as mood, feelings, personal desires, attitudes, or convictions. There must exist agreed procedures for tackling the problem. Above all. there must be general agreement as 
to what counts as a solution. It must be possible for the problem to receive a definitive solution. Academically respectable problems must, in short, have many of the characteristics of puzzles - chess or crossword puzzles for example - as emphasized by Kuhn in connection with what he has called 'normal' science. ${ }^{12}$ Such problems arise quite essentially within the context of specialized disciplines, where there are agreed methods, results, assumptions, procedures. It is precisely by excluding all that is vague, ambiguous, controversial, metaphysical, or philosophical that such academically respectable problems can be formulated or created. In order to be in a position to understand, solve, and assess proposed solutions to. such problems one needs to be an expert, with specialized knowledge of the relevant discipline, its methods and results. It is not in general necessary to have broad intellectual or cultural sympathies and understanding. By and large, ignorance of social, political, religious, moral, and philosophical issues lying beyond the scope of his discipline does not in any way hamper or disqualify the expert in his professional work. A 'mere' expert or specialist can be as well equipped as anyone to make outstanding contributions to his discipline.

Experts can be in a position to pronounce authoritatively and definitively on matters that fall within the field of their specialized knowledge. In addition, only experts can be in a position to make such authoritative pronouncements: the rest of us cannot legitimately challenge or criticize expert judgments unless we too have specialized knowledge. Scientists and scholars are thus fully justified in ignoring criticism of their work and results by 'outsiders', by those without expertise. The price that the expert pays, however, in being able to make unassailable, authoritative judgments is that he must confine himself, qua expert, to delivering judgments that lie within the limited sphere of his professional competence - that small part of his discipline about which he does have expert knowledge. He must not in his capacity as expert make pronouncements about broad political, moral, religious, and philosophical issues - the immensely complex human, social problems of real life-which, in their very nature, cannot be amenable to specialized, academic treatment.

Specialism may seem to represent an intolerably narrow-minded, dogmatic, scholastic conception of intellectual inquiry. All that is adventurous, imaginative, speculative, free-ranging, and creative may seem to be excluded from science and scholarship. Those who defend specialism, however, usually do so in terms of the following kind of argument. It is precisely by eschewing consideration of imaginative, speculative, imponderable issues, and instead concentrating attention on much more limited, specialized "puzzles', capable of definitive solutions, that science and scholarship have made such giant steps forward in recent times. In the end. sustained attention paid to limited, technical problems pays dividends, and may even result in a definite solution to some 'profound' philosophical problem. The problem of how the human race has come into existence has been discussed fruitlessly for centuries. Not until the work of Darwin was any real contribution made towards solving this 'philosophical' problem. The crucial point about Darwin's contribution, however - so the argument goes - is that it arose out of painstaking attention to highly detailed, limited, specialized problems within zoology and botany. ${ }^{13}$

It is, I hope, obvious from the above that according to specialism the four basic problems of fundamentalism lie wholly outside the field of reputable science and scholarship. Inevitably these four problems are such that there can be no general agreement as to how they ought to be formulated, or what methods ought to be adopted in seeking to solve them. It is most improbable - perhaps even undesirable - that there should ever be general agreement as to what is to count as a correct, acceptable solution to any of these problems. And it is extremely unlikely that any of them will receive a definitive solution. The four basic problems of fundamentalism satisfy none of the requirements which specialism demands of academically reputable problems. Thus, according to specialism, discussion of these four problems has no place at all within scientific, academic inquiry. Academic inquiry may perhaps produce work that has some bearing on the answers we give to the four basic questions, as in the case of Darwin's work. This comes about, however, as a result of aiming at solutions of exclusively specialist, technical problems. The four basic problems of fundamentalism only have a place within academic inquiry at one remove, as it were, within anthropology, sociology, or the history of ideas. A historian of ideas, for example, may quite legitimately discuss the writings of those who have speculated about such problems. Such a historian will however be concerned to solve specialized problems within his field, concerning the evolution of ideas. He will not concern himself with the fundamental problems as such- not if he is to continue to function as an intellectually reputable academic.

Extreme versions of specialism - such as logical positivism - condemn the four basic fundamentalist problems as metaphysical and evaluative, and therefore strictly meaningless. Less extreme versions of 
specialism merely place them outside the domain of intellectually respectable scientific, academic inquiry.

\section{III}

Fundamentalism and specialism uphold diametrically opposed intellectual standards.

According to fundamentalism, it is absolutely essential for the rationality, intellectual rigour, and integrity of intellectual inquiry as a whole that sustained attention be given to the four basic problems. Indeed, this attention needs to be given intellectual priority over all else. All other intellectual activity needs to be subservient to the central and fundamental activity of imaginatively proposing and critically assessing possible answers to the four basic problems. Only in this case can even the most elementary of requirements for rational problem-solving be realized.

According to specialism, on the other hand, rationality, intellectual rigour, and integrity, actually demand that the four 'basic' problems of fundamentalism be placed outside the domain of reputable intellectual inquiry. Mature science, authentic scholarship, genuine intellectual progress only really get underway when inconclusive philosophical debate about fundamental issues has been put firmly aside. $^{14}$

One important aspect of this difference in intellectual standards is that fundamentalism and specialism uphold different conceptions of intellectual progress.

According to fundamentalism, intellectual progress is to be conceived in terms of the success that intellectual inquiry has in enabling us to improve our answers to the four fundamental problems, and to improve our capacity to tackle these problems in a rational fashion. One might say that fundamentalism, ultimately, conceives of intellectual progress in personal and social terms - in that what is at issue is the answers that people in fact give to fundamental questions in their lives. Our assessment of intellectual progress will of course depend to some extent on the kind of tentative, broad answers that we give to these questions. Intellectual progress itself is no doubt something absolute and definite; our assessment of intellectual progress, however, is bound to be somewhat tentative, it being possible for there to be a number of different legitimate assessments.

According to specialism, on the other hand, intellectual progress is to be conceived in terms of the success that intellectual inquiry meets with in solving specialized, technical, scientific/academic problems. Progress -or the lack of it - is thus something definite, uncontroversial, something about which there can be general agreement. This is especially true for science. According to specialism, all scientific problems are essentially problems we encounter in seeking to predict more and more phenomena more and more accurately. Thus scientific progress is to be assessed simply in terms of the success we meet with in developing laws and theories which predict more and more phenomena more and more accurately. ${ }^{15}$

\section{IV}

Actual scientific, academic inquiry, as it exists at present, and has existed during the last hundred years or so, amounts to an uneasy admixture of fundamentalism and specialism. In many ways, however, specialism predominates.

It must of course be acknowledged that some aspects of scientific, academic inquiry do exemplify fundamentalist standards. For example, there can be no doubt that science, technology and scholarship have made great progress when viewed from a fundamentalist perspective. The special and general theories of relativity and quantum theory have changed profoundly our conception of the physical universe. The theory of evolution, and subsequent developments since Darwin's day, have done much to improve our understanding of how we fit into the world and have come to be. Our whole conception of the cosmos has been utterly transformed during this period. Technological research has done much, potentially and actually, to provide us with the means to create a better human world. Research in history, archaeology, anthropology - and more questionably, research in other social sciences and humanities - has deepened our understanding of ourselves, our past, our potentialities.

In addition to this there have been many noteworthy 'fundamentalist' thinkers who have consciously sought to help solve one or other of the four fundamental problems. Almost at random one might mention: Einstein, Freud, Schrodinger. Eddington, Russell, Whitehead, Poincare, Jung, Erich Fromm, Margaret Mead, Karl Popper, Carl Sagan, E. Schumacher, I. Illich, T. Szasz, F. A. Hayek, A. Koestler, T. Roszak, H. Marcuse, R. May, R. Higgins, ${ }^{16}$ and of course many others of varying repute. 
In many ways, however, the influence of fundamentalism on actual scientific, academic practice is submerged beneath the massive influence of specialism on all but a minute proportion of scientific, academic work. Most scientists and scholars are specialists, concerned only to solve specialist problems not consciously conceived of as sub-problems of the four fundamental problems. Almost all scientific, academic publications are concerned with the resolution of specialist problems. Education is shaped primarily by specialist assumptions and standards, especially towards the upper end of the educational ladder, culminating as it does in the extreme specialism of the Ph.D. thesis. Academic appointments, academic honours, academic success, are all judged in terms of specialist standards apart from quite exceptional cases.

Perhaps most crucially of all, the over-all organization, the institutional structure, of scientific, academic inquiry exemplifies specialism rather than fundamentalism. Universities are split up into relatively autonomous faculties: for example, faculties of physical sciences, biological sciences, technology, medicine, humanities or arts. Each faculty is subdivided into a number of relatively autonomous departments corresponding roughly to distinct academic disciplines. On the intellectual level, however, the subdivisions proceed further: each discipline is subdivided into a number of subdisciplines: a specialist whose field of expertise lies within such a sub-discipline may not even be able to communicate properly - let alone share problems - with colleagues working within the same discipline. Such an expert will communicate almost exclusively with his fellow specialists scattered throughout the world - thus participating in what has been called an 'invisible college'. ${ }^{17}$

The striking point to note about all this is that nowhere is any provision made whatsoever for sustained, explicit, influential discussion of fundamental problems. This does not exist at the level of individual universities; nor does it exist at the level of published intellectual discussion, at the level of 'invisible colleges'. ${ }^{18}$ Scientific, academic inquiry is, in other words, organized overwhelmingly in accordance with the intellectual standards of specialism.

All this has dire intellectual consequences - especially, of course, if viewed from the perspective of fundamentalism. The remorseless concern to solve exclusively specialist problems for their own sake, the proliferation of specialized disciplines (disciplines within disciplines, the autonomy of each jealously guarded), the accumulation of specialized results and vocabulary, increasingly specialized education (specialist indoctrination), the absence of informed, critical, non-technical discussion of fundamental issues - all these factors combine to make it overwhelmingly difficult for anyone to discover, understand, and use the fundamentalist implications of specialized results. Intellectual inquiry becomes increasingly fragmented and incoherent, increasingly unusable from the standpoint of helping us to improve our answers to the four fundamental questions.

That over-specialization can have undesirable consequences has, it is true, been rather widely recognized. This scarcely amounts, however, to a recognition of the inadequacy of specialism. For if we look at what has been done in an attempt to compensate for fragmentation brought about by overspecialization, we find that new interdisciplinary subjects have been created, subjects such as biophysics, biochemistry, mathematical logic, industrial sociology. This typically specialist way of attempting to solve the problem actually, in many ways, serves only to make it worse. In seeking to facilitate communication between disciplines, additional buffer disciplines are created which only have the effect of further obstructing interdisciplinary communication. Thus even those who seek to combat some of the bad consequences of specialism can only adopt specialist methods in seeking to do so - so powerful a hold does specialism exercise over the academic mind - the end result being in consequence the exact opposite of what was originally intended. What cannot be done, of course, is what is needed most: the development of a tradition of influential, informal discussion of fundamental problems, feeding into, and being fed by, diverse specialist discussion. This obvious solution cannot be adopted for the simple reason that it involves violating specialist intellectual standards !

A further powerful indication of the increasing predominance of specialism over fundamentalism is provided by the way in which academic philosophy has developed in recent times. Increasingly, academic philosophers have been concerned to develop philosophy as an academically respectable specialized discipline, with its own particular problems and methods, existing alongside other academic disciplines. For the vast majority of academic philosophers, progress in philosophy is to be achieved by pinpointing and solving technical problems mainly conceived as problems of 'conceptual confusion' requiring 'conceptual analysis'. ${ }^{19}$ Fundamentalism, of course, becomes quite impossible if 'philosophy' is pursued in this specialized way. For fundamentalism requires the existence of the Enlightenment conception of philosophy - philosophy conceived as the open, non-professional, 
unspecialized discussion of fundamental problems, influencing and being influenced by specialized problem-solving in all other scientific, academic disciplines. In seeking to " develop academically respectable, professional, specialized philosophy, academic philosophers have sabotaged almost all possibility of developing intellectual inquiry in fundamentalist directions.

Consider the following specialist account of the way in which intellectual inquiry has developed over the centuries.

'Intellectual inquiry begins with myth, religion, and philosophy. Originally, philosophy (or perhaps theology or metaphysics) is the queen of the sciences, other intellectual disciplines having only a highly subservient, specialized role to play within philosophy. This state of affairs exists in the thought of ancient Greece, in the thought of Mediaeval Europe, and, to some extent, in the thought of seventeenth-century Europe during the so-called scientific revolution. For Kepler, Galileo, Bacon, Descartes, Newton, Spinoza, and Leibniz, philosophy and theology represented the primary, central disciplines - so much so that science was known as "natural" or "experimental" philosophy. Gradually, however, successive disciplines emerged out of philosophy, dissociating themselves from the parent discipline of philosophy, intellectual success and progress being essentially bound up with this long process 'of dissociation. Over the centuries philosophy has given birth to the autonomous disciplines of mathematics, astronomy, physics, logic, biology, history, political science, sociology, psychology, cosmology, linguistics (the last three or four only having become autonomous in the twentieth century). As a result of having bred these autonomous disciplines, philosophy itself has been left in a highly impoverished state. The nature and status of philosophy, in other words, have changed dramatically. Instead of being the queen of the sciences, overarching all other sciences, philosophy has been transformed into a highly specialized, technical, somewhat meagre enterprise, concerned not with improving our knowledge and understanding of the world -for that is the business of the empirical sciences-but rather with clarifying concepts and solving conceptual problems. In line with the general trend, academic philosophy seeks to transform itself into a specialized discipline, dissociated from "philosophy" in the original sense of Plato, Spinoza, Leibniz, Diderot, Voltaire, Hume or Kant. ${ }^{20}$

It must be admitted, I think, that this specialist account of intellectual history does considerable justice to the way intellectual inquiry has in fact developed over the centuries. Furthermore, this account is today in practice widely upheld throughout the scientific, academic world as providing us with an adequate account of how intellectual inquiry ought to develop. Scientists and scholars have had something like this account in mind in pursuing and developing diverse disciplines. Above all, most contemporary academic philosophers take for granted the conception of modern philosophy that emerges from this account. ${ }^{21}$ All of which provides a strong indication of the extent to which specialism has come to be built into the institutional framework of contemporary scientific, academic inquiry.

Fundamentalism, of course, provides us with a quite different picture of how intellectual inquiry ought to develop. If intellectual inquiry begins with myth, religion, philosophy, metaphysics, this is because intellectual inquiry begins quite properly with a concern with the above four fundamental questions. Intellectual progress requires, of course, the development of specialized disciplines concerned to solve diverse subordinate and preliminary problems. It is of crucial importance, however, according to fundamentalism, that this development occur in such a way that we can, all the more readily, tackle the four fundamental questions in a rational fashion. The development of autonomous disciplines - the essential feature of the specialist account - violates the most elementary rules of rational problemsolving.

None of the above, however, captures that feature of present-day scientific, academic inquiry which constitutes the most blatant and harmful institutional embodiment of specialism. This feature concerns, not so much the internal intellectual-institutional structure of scientific, academic inquiry, but rather the way in which scientific, academic inquiry is related to society, life, and the problem-solving that goes on in all our personal and social lives. According to the version of fundamentalism that I wish to defend, the basic task of professional scientific, academic inquiry is to help all of us to recognize and resolve rationally those problems we need to resolve in order to discover and achieve that which is most desirable and of value in life. The basic task of fundamentalist academic inquiry is to help us to put fundamentalism into practice in our personal, social lives, and to help us to develop a social order, a world, in which cooperative rational resolving of our most important personal and social life-problems may receive every encouragement. For this goal to be realized, there must be a constant two-way flow of ideas and arguments between discussion of fundamental problems in society, as a part of life, 
and discussion of fundamental problems within professional scientific, academic inquiry. An intimate, two-way, rational relationship needs to exist between society and science, life, and scholarship.

At present this vital rational socio-cultural relationship scarcely exists anywhere. This is largely due to the prevalence of specialism which prohibits the above rational social relationship. Specialism demands precisely that scientific, academic inquiry, in order to be intellectually rigorous, must be such that the intellectual domain of scientific, academic inquiry is decisively dissociated from the discussion of problems that goes on in society, as a part of life. Scientists and academics, upholding specialist intellectual standards, have done their utmost to develop and preserve this dissociation - in order, from their own standpoint, to preserve rigorous intellectual standards. As a result, the scientific, academic community has betrayed its most profound intellectual purpose (as seen from the perspective of fundamentalism): to help us develop more rational, wiser ways of living, a more rational, wiser world. The result of this betrayal, not surprisingly, is that the production of specialist knowledge flourishes, while wisdom in life, world-wide wisdom, falters.

Of the two views under consideration, it is fundamentalism, and not specialism, which provides us with a rational, intellectually rigorous conception of intellectual inquiry.

In assessing the relative merits of the competing doctrines of fundamentalism and specialism, it is vital to recognize that fundamentalism fully acknowledges the immense value of- indeed the absolute necessity for-specialized scientific, academic work and thought. It is often only by putting into practice the two basic rules of rational problem-solving (c) and (d), formulated above in Section II, that it is possible to make any headway with improving our solutions to our fundamental problems. Specialized problem-solving, specialized scientific, academic work is absolutely essential, according to fundamentalism, for rational problem-solving in general. The decisive additional point insisted on by fundamentalism is that it is absolutely essential to put into practice rules (a) and (b) too. There must be a sustained rational discussion of our common, fundamental problems both within the scientific, academic community and within society, intimately inter-connected with specialized scientific, academic problem-solving if intellectual inquiry is to serve our best interests in a genuinely rigorous, rational fashion. It is legitimate, even desirable, that many individual scientists and scholars be absorbed by the pursuit of highly restricted, specialized topics and problems. What is vital is that the over-all intellectual-institutional structure of scientific, academic inquiry and of society itself accord with the kind of hierarchical structure required by fundamentalism - sustained, explicit attention being given to fundamental problems. Failure to put into practice - to institutionalize - this vital fundamentalist perspective must inevitably lead to the fragmentation and trivialization of intellectual inquiry, and to a general incapacity to tackle cooperatively and effectively mankind's fundamental problems. The institutionalizing of specialism, however, obliges us to neglect the fundamentalist perspective. As a result we cease to tackle rationally just those problems it is most important for us to tackle rationally. While diverse sub-problems may be brilliantly tackled, our most general and important problems fall into neglect.

The motivation for insisting that it is of the essence of rationality to articulate our basic problems, and to propose and criticize possible solutions, is really very simple. If we do this, we give ourselves the best chance of seeking to solve those subordinate problems which are relevant to our main objectives. If we do not do this, the chances are that we will become engaged in seeking to solve sub-problems which are entirely misconceived or wholly irrelevant from the standpoint of achieving our basic objectives. Putting specialism into practice, in other words, is almost bound to lead to a mass of problem-solving activity which is misconceived or irrelevant from the standpoint of what matters most in life-a fair comment, I suggest, on a great deal of scientific, academic inquiry as pursued at present.

What if no serious doubts really arose as to how we should answer the fundamental questions: What kind of world is this? How do we fit in? How have we come to be ${ }^{9}$ What is of most value in life? How can we help develop a better human world? In that case fundamentalism would be somewhat redundant. Serious doubts presumably would only arise in connection with much more specific, particular issues. But this is not our situation. The above questions are all profoundly problematic, even if many people appear not to recognize the fact. Our greatest uncertainties simply do arise in connection with our most general and important problems. This being the case, it is essential that we give intellectual priority to the critical discussion of these problems, granted that we seek to develop a genuinely rational kind of intellectual inquiry.

Specialism is thus to be rejected, on the grounds that it provides us with a conception of intellectual 
inquiry that is both irrational and humanly undesirable, these two features indeed being intimately connected. Instead of prompting us to attend to what is most important and problematic, specialism does precisely the opposite!

The harmfulness of specialism does not lie in its tendency to encourage specialized puzzle-solving. Fundamentalism, too, insists on the vital importance of such puzzle-solving. Nor need the harmfulness of specialism lie primarily in any tendency actively to suppress inquiry into fundamental problems. An upholder of specialism may simply see thought about fundamental problems as yet another specialized intellectual enterprise -grotesquely bankrupt intellectually, it is true, but scarcely deserving to be suppressed for all that. No, the real harmfulness of specialism arises from the fact that it appears to justify the pursuit of specialized problem-solving divorced from the consideration of fundamental assumptions and problems. Worse, specialism holds that intellectual integrity and respectability actually demand that fundamental assumptions - vague, conjectural, controversial - be excluded from specialized inquiry. As a result, the adoption of specialism leads to the development of specialized inquiries - within a multitude of diverse disciplines - all of which become immune to elementary, outside, fundamental criticism.

This feature of specialism is responsible for such widespread intellectual corruption in present-day scientific, academic inquiry, that it deserves further comment. The key point that needs to be recognized is that it must always be irrational and undesirable to pursue specialized problems isolated from all consideration of fundamental problems. This is because the whole paraphernalia of specialized problem-solving, as described above, actually requires us to give answers to fundamental problems. Choice of problems, formulation of problems, methods of attack, criteria for acceptable solutions, criteria for progress - all these essential features of specialized problem-solving implicitly presuppose more or less broad answers to the four basic questions - answers all too likely to be more or less false or unacceptable and standing in need of improvement. If specialized puzzle-solving cuts itself off from all critical consideration of fundamental issues (as specialism requires), then such puzzlesolving becomes irrational in the straightforward and basic sense that implicit, influential, and controversial assumptions are made which are permanently protected from critical assessment. Only by openly acknowledging the basic metaphysical and evaluative presuppositions implicit in specialized puzzle-solving can such puzzle-solving become genuinely rational.

It is above all the enormous success of science - conceived of in traditional empiricist terms which has seemed to provide the most powerful case for specialism, and for the central assumption that specialized problem-solving needs to be dissociated from fundamental assumptions and problems.

According to fundamentalism, a basic task of science is to help us to improve our answers to the question: What kind of world is this? Thus according to fundamentalism a genuinely rational science, putting into practice the two most elementary rules of rational problem-solving, gives intellectual priority to the task of proposing and criticizing answers to this question. Proposing and criticizing rival comprehensive metaphysical views about the nature of the universe, the nature of reality, constitutes, in other words, a central intellectual activity of a genuinely rational science. Metaphysical assumptions at this level will influence drastically more restricted, specialized scientific problem-solving - the kind of methods adopted, the kind of theories developed and tested. Thus if we believe ourselves to be in some kind of animistic universe - or in an Aristotelian universe we will adopt different methods and develop different theories from those which we will adopt and develop if we hold, in Galileo's words, that 'the book of Nature is written in the language of mathematics'. The success of modern science, according to this standpoint, is due in large measure to the fortunate choice of a comprehensive metaphysical conception of Nature - shared by Kepler, Galileo, and their successors -which sets the stage for a characteristic kind of specialized problemsolving. According to this fundamentalist standpoint, then, science needs to be understood in terms of an interplay between fundamental and specialized problem-solving, fundamental ideas and methods evolving with evolving specialized knowledge, this, in part, explaining the explosive growth of scientific knowledge. As our scientific knowledge improves, our knowledge about how to improve our knowledge - our methods - improves as well. All this illustrates the four rules of rational problemsolving formulated above. ${ }^{22}$

Just this fundamentalist conception of science - exemplifying elementary rules of rational problemsolving - is, however, rejected absolutely by almost all contemporary scientists and philosophers of science. For, according to traditional empiricist conceptions of science - almost universally taken for granted within the scientific community - it is the essential, defining characteristic of science that, in 
science, theories are selected impartially with respect to empirical success, independently of their compatibility or incompatibility with comprehensive metaphysical assumptions about the nature of the world. Many, of course, acknowledge that simplicity considerations play an important role in the assessment of scientific theories in addition to empirical considerations (for example Mach, Duhem and Poincare); the decisive point, however, is that biased preference for simple theories in science is not interpreted as committing science to the metaphysical, and possibly false, assumption that the universe itself is simple. According to this traditional empiricist standpoint, science is successful precisely because theories are selected impartially with respect to empirical considerations isolated from all $a$ priori metaphysical assumptions about the nature of the world. This was one of Bacon's main points. (Descartes disagreed: but with the downfall of Cartesian science, and the success of Newtonian science, generally and wrongly held to incorporate Baconian inductivism, Cartesian fundamentalism was rejected by the scientific community.) The diverse philosophies of science of inductivism (Bacon and Mill), conventionalism (Duhem and Poincare) and logical empiricism (Carnap, Hempel, and Nagel) all take for granted that in science theories are selected with respect to empirical success alone, unbiased by metaphysical assumptions about the nature of the universe as a whole. Even those thinkers who acknowledge the importance of a priori metaphysical ideas (Descartes, Spinoza, Leibniz, Kant) miss the essential point of the fundamentalist conception of science outlined above. For instead of emphasizing that our fundamental metaphysical ideas about the nature of the universe are conjectures, more or less bound to be false, and therefore needing constant critical scrutiny and development within science, these thinkers, on the contrary, seek to show, in one way or another, that fundamental metaphysical assumptions or principles can be conclusively established by reason, by argument. In effect empiricists and so-called 'rationalists' agree on one main point: metaphysical principles, unverifiable by experience, have a legitimate place in science only if they can be conclusively established by reason. Rationalists defend the existence of such principles: empiricists, correctly, reject this possibility. Both parties miss the essential point: metaphysical principles play a decisive role in science; these principles are, however, conjectures, more or less bound to be false: hence, if science is to be rational it is essential that these principles be articulated, criticized, and developed as an integral part of the scientific enterprise. Even Russell, it should be noted, misses this point. Russell recognizes that scientific method implicitly makes substantial metaphysical presuppositions about the world: he fails, however, to draw the fundamentalist conclusion from this, namely that a genuinely rational science seeks to improve its metaphysical presuppositions, and its methods, as it progresses. ${ }^{23}$

The point is decisively rejected even by Popper. Popper has many fundamentalist arguments and remarks to his credit. His book The Open Society and its Enemies tackles an issue central to fundamentalism. Popper emphasizes that metaphysical ideas have often played a highly fruitful role in science.$^{24} \mathrm{He}$ has emphasized the importance of 'metaphysical research programmes' for science, some science, in his view, even amounting to metaphysical research programmes (for example, in his view, the theory of natural selection). ${ }^{25} \mathrm{He}$ has argued that metaphysical ideas can be assessed rationally, as more or less adequate, tentative solutions to problems. ${ }^{26} \mathrm{He}$ has stressed that intellectual inquiry needs to be organized, not in terms of subject-matter and disciplines, but rather in terms of problems, and attempts to solve problems. ${ }^{27} \mathrm{He}$ has emphasized that science at its best is cosmology - the attempt, in effect, to answer the question: What kind of world is this $?^{28}$ He has argued for philosophy conceived as a part of our attempt to improve our knowledge and understanding of the world, and against the view that philosophy is merely specialized 'puzzle-solving', or conceptual analysis. ${ }^{29}$ Finally, he has explicitly condemned specialism. Thus, commenting on the attitude of mind of the normal scientist, as described by Kuhn, Popper remarks:

I admit that this kind of attitude exists: and it exists not only among engineers, but among people trained as scientists. I can only say that 1 see a great danger in it and in the possibility of its becoming normal (just as I see a great danger in the increase of specialization, $3_{3}$ thich also is an undeniable historical fact): a danger to science and, indeed, to our civilization.

Elsewhere he remarks:

If the many, the specialists, gain the day, it will be the end of science as we know it-of great science. It will be a spiritual catastrophe comparable in its consequences to nuclear armament.

Nevertheless, the central tenet of Popper's thought in effect lends strength to a mainstay of specialism: namely, traditional empiricism. Much of Popper's later writings elaborate and apply the main thesis of 
his first book The Logic of Scientific Discovery. There Popper seeks to solve a problem central to traditional empiricism, namely how to demarcate science from metaphysics. Popper's solution, of course, is that a theory, in order to be scientific, must be experimentally falsifiable. A discipline, in order to be scientific, must assess theories solely with respect to empirical considerations, priority being given to those theories which have best survived severe testing and are most amenable to being severely tested. In other words, Popper, along with Bacon, Mill, Duhem, Hempel, and others, is centrally concerned to drive a sharp and decisive wedge between the assessment of specialized, partial solutions to scientific problems (laws and theories) and the assessment of solutions to the fundamental problem of science, namely metaphysical answers to the question: What kind of world is this? In Conjectures and Refutations Popper makes the matter altogether explicit when he defends 'the principle of empiricism which asserts that in science, only observation and experiment may decide upon the acceptance or rejection of scientific statements, including laws and theories'. ${ }^{32}$ Dramatically and decisively, Popper rejects the basic tenet of the fundamentalist conception of science, as outlined above.

However, as I have argued at greater length elsewhere,$^{33}$ this 'standard empiricist' viewpoint is unacceptable. The insolubility of the problem of induction as formulated, for example, by Popper, shows clearly that scientific laws and theories - solutions to specialized scientific problems -cannot be assessed solely with respect to empirical success, in an entirely impartial fashion. If we honestly attempted to select theories in this way, we would always be overwhelmed by a vast number of complex, empirically successful theories, and we would fail to select the theories we do actually select in science. In practice, in science selection of theories is permanently biased in the direction of simplicity and unity, even to the extent of over-ruling mere empirical success. This means that in scientific practice, whether we recognize it or not. we presuppose that the universe has some kind of underlying structure (oral least that it behaves as if it had such an underlying structure, to a high degree of approximation). In other words, science is only possible in so far as a more or less specific, tentative answer is given to the question: What kind of world is this? Much of the success of modern science depends upon the aptness of this answer - so we may well judge. The answer is built into the whole methodology of science. In order to pursue science in a genuinely rational fashion, in a fashion which gives us the best hope of making real progress in improving our knowledge and understanding, we need to propose and criticize modified versions of our answer to the question 'What kind of world is this?' as an integral part of science. We need to do this in an attempt further to improve the methods, and the success, of science. We need in short to put fundamentalism into practice. Any attempt, like Popper's, to characterize science in terms of fixed methods which select theories solely with respect to empirical success must fail to solve the problem of induction - simply because science, so characterized, violates the two most basic rules of rational problem-solving: ${ }^{34}$ in addition, the vital capacity of science to develop improved methods with improving knowledge, such an essential feature of scientific progress, must inevitably be missed out. ${ }^{35}$ Instead of holding speculation about the ultimate nature of the universe to be metaphysical, philosophical, and thus of questionable scientific status, if not downright unscientific or even meaningless, we need, rather, actively to pursue such speculation, imaginatively and critically, as an integral part of science itself. We need to put into practice the kind of fundamentalist way of doing science so brilliantly initiated and exploited by Einstein, in developing the special and general theories of relativity. ${ }^{36}$

That specialized scientific problem-solving requires some kind of answer to be given to the question 'What kind of world is this?' has been vividly and dramatically demonstrated by Kuhn in his book The Structure of Scientific Revolutions. Kuhn establishes convincingly that the 'puzzle solving' of normal science depends upon the acceptance of a paradigm-in effect a Weltanschauung, a view of the world, for a given scientific discipline. One might well suppose that Kuhn, having realized this crucial point - this decisive objection to specialism - would go on to defend fundamentalism, and the need for sustained development and criticism of 'paradigms' as an integral part of science. Kuhn, of course, does exactly the opposite. Discussion of fundamental issues has, for Kuhn, no place within a 'mature' science. ${ }^{37}$ Furthermore, for Kuhn, changes of paradigm - scientific revolutions - inevitably involve a breakdown of rationality. Instead of emphasizing that rational assessment of paradigms is essential for the rationality of the whole of science - as fundamentalism does -Kuhn, on the contrary, declares that choice of paradigm in general lies beyond the scope of reason. ${ }^{38} \mathrm{Kuhn}$, in short, is quite unable to conceive of nonspecialist standards of rationality. The Structure of Scientific Revolutions brilliantly reveals the glaring defect of specialism, and yet, perversely, is itself a defence of specialism, of specialist intellectual 
standards. This provides yet another illustration of the powerful hold that specialism has over the academic mind - especially when one takes into account the great success of Kuhn's book in academic circles.

The profound irrationality of science as depicted by Kuhn in his book can perhaps be brought out by considering the following comparison. Our problem, let us suppose, is to wend our way through an obstacle-strewn path, from $A$ to $B$ (from ignorance to knowledge). Kuhn's advice is to proceed as follows. Standing at A, arrive at a general idea as to how to get to B (a paradigm); then, with head down one might almost say with eyes shut- set off, sticking rigidly to this general idea. Even if you bump into a wall, fall into a ditch, or get tangled in brambles (anomalies), nevertheless adhere rigidly to your route (normal science). However, if you seem to have got into permanent difficulties (crisis), you may open your eyes, look around, and hit upon a new route (revolution), which, however, you must stick to as rigidly as before (new phase of normal science).

This blind blundering about may eventually bring you to your goal $B$. It is hardly, however, the most intelligent, the most rational way to proceed.

$A$ rather more sensible procedure is to keep one's eyes open, and continuously adjust one's route (paradigm) in the light of what one sees and learns on one's way from $A$ to $B$. In order to pursue science intelligently and rationally, in other words, we need to reconsider, explicitly and persistently, our most fundamental paradigmatic ideas as an integral part of science. Instead of adhering blindly and dogmatically to some paradigm until our difficulties have become overwhelming and we are forced to reconsider, we need rather to attempt to improve our paradigm even before insoluble empirical problems overwhelm us, taking into account important $a$ priori considerations such as simplicity, coherence, unity, intelligibility, comprehensiveness. This was the way Einstein developed the special and general theories of relativity; Einstein was much too intelligent, and much too interested in discovering the 'thoughts of God', to follow Kuhn's advice. ${ }^{39}$

To sum up this part of the discussion, specialized scientific problem-solving cannot proceed unless some kind of answer is given to the question 'What kind of world is this?'. This answer is almost bound to be more or less wrong, standing in need of improvement. Hence it needs explicit, sustained, critical discussion. ${ }^{40}$ Specialized scientific problem-solving dissociated from such fundamentalist discussion is irrational, as our glance at Popper's and Kuhn's work has shown.

Analogous considerations arise in connection with all other specialized academic disciplines, and in connection with the other three fundamental problems. Inevitably, in pursuing specialized lines of research, in history, for example, in literary criticism, anthropology, sociology, psychology, medical research or engineering, we presuppose some kind of rough and ready answer to one or other- or to all of the four fundamental questions, this answer influencing our choice of problems, criteria for successful solutions, and so on. Since such implicit and influential answers are all too likely to be more or less inadequate, it is essential, for rationality, that these answers be explicitly articulated and critically assessed, as an integral part of specialized problem-solving. ${ }^{41}$

In recent years a number of writers-so-called 'externalist' historians of science and sociologists of knowledge - have argued in effect that specialized scientific, academic problem-solving is substantially influenced by the social and cultural circumstances in which it proceeds. Material conditions, religious, political, moral, and social ideals, human interests and values of one kind or another, all influence intellectual inquiry. $4^{2}$ (This may be understood as a generalization of the Kuhnian point that specialized scientific problem-solving is influenced by paradigmatic assumptions.) Specialism insists that such nonrational influences must be kept to a minimum, and must be excluded altogether when results are being assessed, if intellectual inquiry is to retain its rationality and objectivity. Fundamentalism, on the other hand, insists that such influences must be openly acknowledged and critically scrutinized if intellectual inquiry is to be rational and objective. If our task is to discover what is of value in life, and to help develop a better human world, then of course our thinking must not be dissociated from our personal and social lives, from our material circumstances, our political, moral, and religious ideals, our desires and values. A basic task of intellectual inquiry must be to promote more rational problem-solving in life - thus gradually helping us to develop a more rational human world: intellectual inquiry must not merely seek to shield itself from the corrupting influences of an irrational society, as specialism would have it.

Most contemporary externalist historians of science and sociologists of knowledge would probably agree that the specialist programme of excluding social and cultural influences from intellectual inquiry cannot succeed, and is even perhaps incoherent. One might suppose that as a result of recognizing the general untenability of specialism, these writers would advocate and practise 
fundamentalism. In fact one finds nothing of the kind. Perversely, like Kuhn, these writers continue to accept and practise specialism - contributing to the highly specialized disciplines of history of science and sociology of knowledge. The main implication of this work is to undermine specialism: but if those who do this work do not themselves see this implication, how can anyone else be expected to see it? Once again we see the extraordinarily powerful hold that specialism has over the contemporary academic mind. ${ }^{43}$

Specialism, then, quite generally, must be rejected. All specialized problem-solving dissociated from fundamental problem-solving must be held to be seriously irrational.

This simple point has profound and far-reaching implications for the whole of scientific, academic inquiry, and for education. For we have seen that scientific, academic inquiry is on the whole at present organized, institutionalized, along specialist, rather than fundamentalist, lines. The urgently needed enterprise of discussing fundamental problems in an informal, informed, critical manner - in a manner capable of influencing, and being influenced by, specialized problem-solving - is obstructed by the prevalence of irrational specialist intellectual standards.

VI

If fundamentalism, and not specialism, provides us with a rational conception of intellectual inquiry, why is it that it is specialism which exercises the predominant influence over most actual scientific, academic work?

The question becomes all the more poignant when we realize how little is new or original in the critique of specialism offered here. Writing over forty years ago now, Aldous Huxley said:

Artistic creation and scientific research may be, and constantly are, used as devices for escaping from the responsibilities of life. They are proclaimed to be ends absolutely good in themselves ends so admirable that those who pursue them are excused from bothering about anything else. This is particularly true of contemporary science. The mass of accumulated knowledge is so great that it is now impossible for any individual to have a thorough grasp of more than one small field of study. Meanwhile, no attempt is made to produce a comprehensive synthesis of the general results of scientific research. Our universities possess no chair of synthesis. All endowments, moreover, go to special subjects - and almost always to subjects which have no need of further endowment, such as physics, chemistry and mechanics. In our institutions of higher learning about ten times as much is spent on the natural sciences as on the sciences of man. AH our efforts are directed, as usual, to producing improved means to unimproved ends. Meanwhile intensive specialization tends to reduce each branch of science to a condition almost approaching meaninglessness. There are many men of science who are actually proud of this state of things. Specialized meaninglessness has come to be regarded, in certain circles, as a kind of hall-mark of true science. Those who attempt to relate the small particular results of specialization with human life as a whole and its relation to the universe at large are accused of being bad scientists, charlatans, self-advertisers. The people who make such accusations do so. of course, because they do not wish to take any responsibility for anything, but merely to retire to their cloistered laboratories, and there amuse themselves by performing delightfully interesting researches. Science and art are only too often a superior kind of dope, possessing this advantage over booze and morphia: that they can be indulged in with a good conscience and with the conviction that, in the process of indulging, one is leading the 'higher life'.

In fairness to Huxley - in order to excuse the mildness of his words here -we must remember how long ago this passage was written. Since that time, before World War II, everything that Huxley speaks of has of course become much worse.

How and why has this happened? In fact, of course, anyone who has sought to put fundamentalism into practice, and who has explored specialized problems for the light they throw on fundamental problems, will have no difficulty in answering this question. Here, briefly, are some factors responsible for the ever-increasing tyranny of specialism.

1. We fail to put fundamentalism into practice primarily because, as Huxley points out, we fail to take up a measure of personal responsibility for the world in which we find ourselves. And we fail to take up such personal responsibility because of the enormous difficulties that we must inevitably encounter at present in seeking to do so. 
These difficulties have arisen as a kind of unforeseen side-effect of the way in which our human world has evolved throughout recorded history. For consider the way in which the problem arises for those who live in the kind of 'human world' experienced by people in pre-historical times -small, closely knit hunting and gathering tribes. In such circumstances, the difficulties that we experience in attempting to assume some personal responsibility for our world do not really arise. Adults - and even children -can without great difficulty assume some measure of personal responsibility for the welfare of the tribe as a whole. All the members of the tribe are known to each individual personally. Relationships of mutual interdependence are experienced daily, on a personal basis, in hunting, gathering food, and so on. Obligations, responsibilities; towards the tribe can be experienced in a personal, emotional way, in terms of known individuals, in much the same way as we can experience responsibilities towards our family today. (Perhaps the modern, family should be understood as a contraction of the pre-historical tribe.) All members of the tribe have a common outlook on things, a common cosmology and system of values. Thus barriers to intimacy, to mutual understanding, do not arise as a result of differences of outlook and values. Individuals do not face agonizing problems of deciding who they are, how they should live, what there is to give meaning and value to life. On the contrary, the meaning and value of life as lived by the tribe is assured, and is even beyond question, in that no alternative is conceivable. Finally, because of the relative small-ness of the tribe, each individual makes a personal impact on the life of the tribe as a whole, and can be well aware of this impact. The tribe, as it were, acknowledges the existence, value and potency of the individual, and is clearly affected by the actions of the individual. ${ }^{45}$

Time passes; agriculture is invented; societies become bigger, more complex, specialized and diversified, requiring much more elaborate, fixed organization. Intertribal trade develops: tribes coalesce. Modern methods of travel, transport, and communications develop, and as a result our tribe has become the whole human world, humanity, even, perhaps, life on earth in general.

As a result of these historical developments, the task of assuming some personal responsibility for our common human world has been transformed utterly, and has become almost inconceivably more difficult. Our task is not only to take on some responsibility for the welfare of those who are known intimately to us: rather, in addition, our task is to assume some responsibility - at least to some extent for the welfare of millions upon millions of complete strangers. No doubt our own welfare is closely bound up with the lives, actions, and welfare of many of these millions of strangers through international relationships such as trade: such relationships of mutual interdependence are, however, remote, abstract, not experienced daily on a personal basis. We cannot conceivably experience direct, emotional ties with these millions upon millions of strangers as we do with our friends and members of our own family. Millions of our fellow human beings live lives, see the world, and have values in many ways very different from our own. Not only does this create barriers to mutual sympathy and understanding: responsible concern to understand others - to enter into their different worlds - must inevitably lead us to question the basic assumptions, practices, and values of our own world. The immense diversity of ways of life, cultures, social systems, views of the world, and systems of values with which we are confronted in considering our common human life on this planet must inevitably, at some level, plunge us into doubt and indecisiveness about how to live, what to choose, what to believe and value. And finally, when put into the context of the whole human world, our own life and actions must inevitably, and quite properly, seem to shrink almost to a vanishing point. Unless we possess quite exceptional personal power or influence - something that is perhaps inherently undesirable - all that we do with our lives will have almost no kind of impact or effect whatsoever on the human world as a whole. From this standpoint we are, individually, insignificant and impotent - which may not exactly encourage us to conceive of our world and ourselves from such a standpoint.

For all these reasons it is extraordinarily difficult for the individual today to assume some personal responsibility for our common world. In earlier times this failure did not perhaps matter so much since our power to bring about world-wide changes was strictly limited. Quite suddenly, however, we have developed the capacity to make drastic changes to our whole world. As a result, our common evasion of responsibility has become extremely dangerous for us all. Disasters result. World-wide war, starvation of millions, immense imbalances of wealth and power on a world-wide basis, the population explosion, reckless squandering of irreplaceable natural resources, international politics conducted like gang warfare, the widespread existence of brutal dictatorships, criminal psychopaths (like Hitler, Papadoc, and Amin) even seizing and holding power, the world-wide accumulation of armaments, the constant threat of the nuclear holocaust - all these familiar world- wide dangers and disasters are the direct outcome of our general failure to assume personal, adult responsibility for our 
world.

The members of a small tribal society can, without great difficulty, confront and tackle common problems of the tribe, in a cooperative, responsible fashion. Tribal meetings can be convened at which everybody can be free to articulate problems, propose and criticize possible solutions.

In our modern world this cannot be done. The population of the earth cannot hold a meeting to discuss common problems where everyone is free to speak. And yet something like this must exist if general understanding of, and responsibility towards, our common human problems is to develop at the personal level - something that we must develop if we are to be able to cope with the dangers and disasters just indicated. We cannot rely on existing institutions, existing centres of power, existing governments, whether democratic or dictatorial: all this is all too blatantly failing at present to cope adequately, i.e. humanely and rationally, with our problems. In the end the point is very simple. In the absence of general understanding of, and responsibility towards, our problems, genuinely democratic governments responsive to public opinion will be unable to act responsibly as far as our most urgent, general, common problems are concerned. ${ }^{46}$ Public opinion will not permit it. In a sense, only undemocratic, dictatorial governments, capable of suppressing or ignoring public opinion, will be able to act in such a fashion. Dictatorships, however, put us at the mercy of the decisions and actions of those few individuals who have won the fight for power (thus being, almost inevitably, ruthless and power-mad). Either way it is most unlikely that global problems will be tackled responsibly. For this we need a widespread, even world-wide understanding of, and responsible attitude towards, our basic problems at the personal level. And for this is turn it is essential that we develop a modern, world-wide institutional equivalent of the tribal meeting.

It is in this way, I suggest, that we need to conceive intellectual inquiry -as the open, sustained, responsible discussion of our common problems. Intellectual inquiry needs to be conceived and pursued as the tribal meeting of humanity, permanently in session, open to all, our joint endeavour to develop cooperative, personal responsibility for our common problems. Something must be created to replace the tribal meeting. Intellectual inquiry, at its best, constitutes such a replacement: it is from this standpoint that intellectual inquiry needs to be understood, contributed to, and judged.

And only fundamentalism can do justice to this conception of intellectual inquiry. This, indeed, is fundamentalism: intellectual inquiry conceived as the outcome of our personal, cooperative, responsible attempts to improve our solutions to our fundamental problems. ${ }^{47}$

The difficulty we experience, then, in putting fundamentalism into practice is an important part of the difficulties we experience in seeking to take on a degree of personal responsibility for our shared world. Specialism is, as Huxley correctly points out, an evasion of responsibility, the outcome of a failure to cope with the stress of responsibility. Specialism can even be seen as the outcome of a kind of intellectual or professional tribalism- the specialist's tribe being the 'invisible college' of likeminded specialists.

A number of writers have been concerned to emphasize - in terms somewhat analogous to those outlined here - that the blessings resulting from moving from the intimate, coherent tribe to the big. complex, diversified modern world are mixed. These writers all emphasize, in one way or another, that this transition makes possible the development of choice, freedom, reason, science, on the one hand, but can also lead to uncertainty, fear, loneliness, a sense of meaninglessness and impotence, on the other hand.

Thus in Coming of Age in Samoa ${ }^{48}$ Margaret Mead tells us that children in Samoa fail to experience anything like the trauma of adolescence so familiar in Western society. She concludes that this is due to the absence in Samoa of the problem of choosing between rival ways of life and values. Adolescent trauma, then, is due to the great difficulties that we experience in coming to terms with cultural diversity in our society - in turn due, without doubt, to a general failure of our culture to cope adequately with this central problem of diversity. As I have already indicated, in The Open Society and its Enemies Popper argues that the open society - the society in which diverse ways of life are tolerated - is essential to our humanity, our reason, our civilization. It is only with the existence of social diversity that we can begin to doubt, to criticize, to learn, and perhaps to make progress. In Popper's view, rationality is to be understood primarily in terms of the capacity to doubt, to criticize, and thus to learn: criticism, however, is only really possible if a plurality of views and ways of life coexist in society. Thus, for Popper, rationality is to be understood primarily in social terms, arising as a result of social developments - the development of social and cultural diversity, and a tradition of criticism. ${ }^{49}$ The development of the open society makes possible the development of both freedom and reason. Popper is at pains to 
emphasize, however, the price we pay for these developments - the strain that civilization puts upon us. It is indeed the major thesis of The Open Society and its Enemies that the uncertainties, the emotional stress, created by our movement towards the open society can be so great that we long passionately for a return to the simplicities and certainties of the monolithic closed society. This anti-rational, antihumanitarian longing is responsible for the totalitarianism of both left and right. The difficulties that confront us in coming to terms with the open society are indeed, according to Popper, so extreme that even many of our greatest thinkers in the past have failed to surmount them: Heraclitus, Plato, Aristotle, Hegel, and Marx all in one way or another, in Popper's view, sought to return us to the closed society. Many of our greatest philosophers and rationalists have been enemies of the open society. ${ }^{50}$

It is scarcely surprising, then, that adolescents, emerging from the 'closed' society of the family into our quasi- 'open' society, should experience difficulties. The problems of adolescence need to be understood in philosophical or rationalistic terms - in terms of emotional reactions to an intense awareness of possibilities and uncertainties-and not merely in terms of some psychological theory of emotional development.

Isaac Bashevis Singer, in his novels and short stories, has given us a wonderfully vivid and perceptive account of the enormous difficulties we encounter in emerging from a closed society. ${ }^{51}$ In The Manor and The Estate Singer provides us with a wholly convincing picture of the confusion, the sense of loss, that overwhelmed those enlightened Jews who, towards the end of the last century, emerged from the highly traditional, almost mediaeval, Jewish communities still existing then in Poland. Singer's writings are especially noteworthy for the fact that many of his protagonists are themselves deeply conscious of the problem, and not merely affected emotionally by it without any understanding of its nature. Singer is concerned to show us, in a fictional form, individuals grappling passionately with the task of pursuing fundamentalist intellectual inquiry. Singer's vivid and honest imagination takes us to the heart of the problems of our civilization.

Essentially the same problems - explored by both Popper and Singer -have also been discussed by Erich Fromm, for example in his The Fear of Freedom. ${ }^{52}$ Finally, Peter Gay, in his marvellous book The Enlightenment: An Interpretation, provides us with a haunting account of the anguish experienced by the thinkers of the Enlightenment in attempting to come to terms with their doubts, their scepticism, as they emerged from the religious tribalism of contemporary Christianity. ${ }^{53}$

It is, I hope, clear that all these writers are concerned essentially with the same problem - the difficulties we encounter in coming to terms with something that is essentially desirable, namely social and cultural diversity. One disastrous consequence of specialism is that it disrupts understanding of problems as fundamental as this: the problem is scattered amongst a number of disparate disciplines, and lost sight of. Instead of discussion being organized around the problem, so that contributions such as those of the above writers can fruitfully interact with, and supplement, each other, discussion is organized instead within the disciplines: anthropology, epistemology, political philosophy, history, psychology, history of ideas, fiction. As a result, we fail to discover the interconnections between the contributions: we fail to improve our understanding of the underlying problem. We fail to understand the problems of adolescence as those of moving from a closed to an open society - in part philosophical problems. We fail to appreciate the social, cultural, and personal implications of Popper's philosophical and epistemological discussions. We fail to grasp the universal significance of Singer's fiction. We do not see that Popper and Singer are concerned with essentially the same problem. Fromm may be dismissed as pursuing the pseudo-scientific discipline of socio-cultural-psychoanalytic psychology, instead of being understood as contributing to our understanding of the problems discussed in The Open Society and its Enemies, and in Feyerabend's 'The Problems of Empiricism.. ${ }^{54}$

Specialism thus prevents us from seeing our fundamental problems. As a result, we fail to see the urgent need to improve our thinking at this level, and the considerable difficulties that arise in connection with this task.

2. It is in the nature of fundamentalism to raise questions and doubts that can be highly awkward for those who wield power in society. In particular, of course, fundamentalism challenges all those who claim to have authoritative answers to fundamental problems - religious and secular centres of power and influence in society. Fundamentalism calls into question cherished beliefs and values, and thus also is liable to collide with public opinion. Powerful social forces, then, will inevitably discourage the development of fundamentalist intellectual inquiry - as Socrates, Galileo, and Spinoza, for example, found out. Only a society which had, quite generally, taken fundamentalism to heart would encourage the development of fundamentalist intellectual inquiry: but of course no such society has as yet come 
into existence.

The case of specialism is, however, quite different. Specialist scientists and scholars may well be quite content to let non-academic authorities decide fundamental issues, scientific, academic inquiry confining itself to solving those specialized, technical problems whose solutions are required by those who wield power in society. Fundamentalist issues in any case lie beyond the reach of specialist intellectual standards and concerns. Specialism thus robs the scientist and scholar of the capacity, from a professional standpoint, to criticize fundamentalist decisions made on the basis of power in society except where those in authority are foolish enough to transgress specialist standards and results.

3. Specialism is especially appealing to those who uphold what may be called 'oracular' conceptions of reason - according to which reason, ideally, is something that reaches decisions for us, rather than being something which helps us to decide. In terms of such oracular conceptions of reason, fundamentalism is, of course, indefensible. ${ }^{55}$

But all such oracular conceptions of reason must be rejected. We may identify reason with some set of rules, laws, methods, or criteria which dictate decisions to us. It ought always to be, however, our own decision to adopt these laws, methods, etc. Genuine rationality involves being able to choose and develop such laws to suit our purposes. Fundamentalism is correct in insisting that genuine rationality involves recognizing that ultimately we choose and decide.

4. According to specialism, the expert is entirely entitled to pronounce authoritatively on matters relating to his discipline - in a manner which ignores the contributions, the criticisms, of non-experts. This is because, according to specialism, only specialized considerations can be relevant for an assessment of specialized results. Only the expert can be competent to contribute to a specialized discipline. There can be no doubt that being able to pronounce authoritatively in this kind of way is something that is deeply appealing to many. Fundamentalism, however, deprives the expert of this deeply appealing authoritative immunity from outside criticism. Basic assumptions about the nature of the world, and about the meaning and value of life, must inevitably, according to fundamentalism, pervade specialist work. It cannot be correct for experts to decide for the rest of us what these assumptions should be. It is thus entirely proper that non-experts should be able to challenge and contribute to fundamentalist assumptions implicit in specialized work. It is indeed important that experts do listen to non-expert comments and criticisms concerning fundamental assumptions, since it is all too easy for the expert to forget the prevalence and influence of such assumptions amidst his technical work - losing sight of the wood for the trees.

5. Increasingly, during the last fifty to one-hundred years, scientific, academic work has become something that is engaged in as a profession, a career, rather than out of amateur love. The scientific, academic enterprise has become increasingly institutional and bureaucratic in character. All this favours, and almost requires, specialism. For these factors require that scientific, academic work can be assessed in a definite, agreed way, sound work being distinguishable from unsound work in an uncontroversial manner. Promotions, funding of research work, professional status, management of research - these career and institutional matters all favour the adoption of definite, agreed specialist intellectual standards. Sustained inquiry into fundamental problems is much more difficult to professionalize and institutionalize. Crucial institutional questions such as whose work is to receive funds, be taught, be rewarded with promotion and academic honours, become almost impossible to decide in a standard, bureaucratic manner. ${ }^{56}$

6. Once a conception of intellectual inquiry has become established - built into the institutional and bureaucratic structure of intellectual inquiry - all sorts of mechanisms tend to preserve this institutionalized conception. Education will tend to indoctrinate pupils and students in this conception. Only those who conform to the standards of the conception will be able to do research work, publish, obtain academic jobs. Only that work which conforms to the accepted standards will be published, and will be accepted on publication. Even those who disagree with the institutionalized viewpoint will be obliged to pay lip service to it, simply in order to teach, publish, and do research. As a result, the public face of scientific, academic inquiry will come overwhelmingly to conform to the general viewpoint, and it will seem increasingly absurd to call this viewpoint into question.

Once specialism is established institutionally, in short, no problem arises as to why this viewpoint 
should persist.

These, then, are some of the factors responsible for the failure to put fundamentalism into practice responsible for a pervasive corruption of intellectual standards.

\title{
VII
}

If fundamentalism were to be put into practice we would expect intellectual inquiry as a whole to give priority to our most general and important problems - specialized problems being chosen and tackled in order to help us solve the former.

The result to be expected from putting specialism into practice is, however, the exact opposite. Although specialized, technical problems may well be tackled with brilliance and great success, from the standpoint of what matters most in life the vast industry of specialized problem-solving may well seem largely irrelevant. Most specialized problem-solving will be unrelated to our fundamental problems. Specialized problems will not be understood or tackled as subordinate problems to fundamental problems. Instead of illuminating our understanding of how fundamental problems may be solved, intellectual inquiry will tend to do the exact opposite. We will tend to be overwhelmed by a vast maze of specialized disciplines, jargon, and results. It is not just intellectual inquiry as a whole that will suffer as a result. We will suffer. Our capacity to think and act intelligently, in response to our basic problems, will be sabotaged. Experts will become, not our servants, but our masters.

In his Nobel peace prize lecture, Martin Luther King declared:

\begin{abstract}
Modern man has brought this whole world to an awe-inspiring threshold of the future. He has reached new and astonishing peaks of scientific success. He has produced machines that think and instruments that peer into the unfathomable ranges of interstellar space. He has built gigantic bridges to span the seas and gargantuan buildings to kiss the skies. His airplanes and spaceships have dwarfed distance, placed time in chains, and carved highways through the stratosphere. This is a dazzling picture of modern man's scientific and technological progress.

Yet, in spite of these spectacular strides in science and technology, and still unlimited ones to come, something basic is missing. There is a sort of poverty of the spirit which stands in glaring contrast to our scientific and technological abundance. The richer we have become materially, the poorer we become morally and spiritually. We have learned to fly the air like birds and swim the sea like fish, but we have not learned the simple art of living together as brothers.
\end{abstract}

The predominance of specialist intellectual inquiry plays its part, I suggest, in the development of the 'glaring contrast' to which Martin Luther King here refers - the achievement of specialist knowledge at the expense of the achievement of wisdom.

Consider the following analogy. Our problem, let us suppose, is to build a house. On the one hand we may tackle this problem in a fundamentalist manner. We propose and criticize possible solutions to our basic problem - thus developing an over-all plan. In order to solve our basic problem, however, a host of specialized, technical, subordinate problems need to be solved. Bricks need to be made; so, too, slates, doors, window frames, windows, beams, plaster, floorboards, and so on. Foundations need to be dug and cemented. AH the various parts need to be assembled properly, in conformity with the plan, to build the house. Plumbers need to put in pipes, tanks, sinks, a bath; electricians need to wire the house; and so on. An intricate maze of highly specialized, technical problems need to be solved by an army of experts if the house is to be built. Equally, however, if the house is to be built, it is absolutely essential that the specialized problem-solving be properly coordinated so that it all gives rise to a solution to the fundamental problem - to build a house. There needs to be a constant two-way flow of information between problem-solving at the fundamental level, and at the specialized level. Failure to solve certain specialized problems may necessitate a revision of the basic plan.

This common-sense fundamentalist approach is in complete contrast to a specialist approach. According to specialism, building a house only involves solving specialized, technical problems. The fundamental problem - what kind of house do we want? - is not a problem that the building trade can take seriously. (It is meaningless, subjective, incapable of being decisively solved, philosophical, evaluative or religious; in any case not a matter for the trade to concern itself with professionally.) The building trade needs to concern itself with specialized, technical 'puzzles' - manufacturing bricks, mortar, cement, slates, floorboards, windows, wiring, pipes, and so on. Progress in the building trade is to be judged in terms of how well these specialized puzzles are being solved.

The outcome of all this will of course be ever increasing piles of completely unusable bricks, slates, 
wire, pipes, etc. - and no house will be built at all. And if we complain, we will no doubt be met with indignation in that each specialist has indeed performed his task with skill and expertise.

The 'house' that intellectual inquiry as a whole should help us build is, I suggest, a life of value - a rich and fulfilling life, a life in which we can share friendship, love, happiness, beauty, creative work, joy in being alive. Our 'fundamental' problems are the problems we encounter in our lives in seeking to discover, experience, participate in, help create that which is of value. The basic rationale for the whole of intellectual inquiry is to help us to articulate and solve these fundamental problems of living. All intellectual problems are subordinate to these fundamental personal and interpersonal problems of living. The problems of mathematics, logic, philosophy, theoretical physics, cosmology, molecular biology, neurology - all these need to be understood as sub-problems of our fundamental personal and interpersonal problems of living.

It is, of course, not the case that intellectual inquiry is pursued only for pragmatic reasons - as a means to the realization of non-intellectual, practical ends. Intellectual inquiry is also pursued for its own sake. Intellectual inquiry is, in other words, itself a part of life, enriching life directly when pursued for its own sake, like music or poetry. It is, for example, of the essence of life of value that we are perceptive and curious about our surroundings - in touch with our environment. 'Pure' research in physics, say, or cosmology, geology, history or anthropology, amounts simply to a cooperative following-up of such personal perceptiveness and curiosity. From the standpoint of pure intellectual inquiry, it is the curiosity, the imaginative explorations, the thoughts and feelings, the knowledge and understanding, the intellectual honesty and passion, the problem-solving, of people in society as a part of life, that really matters. It is our shared exploration of our world, as an aspect of life of value, that is important. It is the personal knowledge and understanding of our world that we have ourselves developed, integrated into our lives, that really matters. Pure intellectual inquiry is, in other words, at the most fundamental level, personal and interpersonal in character, a part of life. The impersonal or institutional aspects of pure intellectual inquiry exist simply as a means to an end: to aid personal and interpersonal curiosity, wonder, knowledge, and understanding, as a vital aspect of our personal and social lives. Thus both 'pure' and 'pragmatic' intellectual inquiry seek to contribute to the richness, the value, of our shared lives here on earth. In both cases, what ultimately matters is the value of our personal and interpersonal lives.

The fundamental aim of intellectual inquiry, we may say, is to enhance our personal and interpersonal wisdom - our capacity to discover and achieve what is of value in life both for ourselves and for others. All intellectual problems are problems subordinate to our basic life-problems of wisdom. Of the four fundamental problems formulated above, it is the third and fourth that are the most fundamental, the first and second being pursued as a part of our concern to discover and achieve what is of value in life.

If intellectual inquiry is to meet with success in helping us to discover and achieve what is of value in life, then it must of course be generally understood to have this basic purpose. Education must enable us to come to understand and use intellectual inquiry in this kind of way ${ }^{58}$ so that we discover fruitful interconnections between our personal problems and 'impersonal', 'objective' intellectual problems, our own personal, childish wonderings about the nature of the universe, for example, illuminating and being illuminated by the 'official' wonderings of Kepler, Newton, Faraday, or Einstein, or our personal problems of adolescence illuminating and being illuminated by the philosophical, social problems of the open society discussed, for example, by Popper, Fromm, Mead, and Singer. Intellectual inquiry must itself be organized in such a way as to be amenable to this kind of understanding and use. Above all, scientists and scholars must be fundamentally concerned to develop intellectual inquiry in such a way that it is designed to help us build our 'houses' of wisdom with our lives. All this is essential if intellectual inquiry is to be developed as the tribal discussion of humanity, designed to help us create more valuable lives, a better human world.

When viewed from this perspective of the philosophy of wisdom, present-day scientific, academic inquiry is, in terms of our analogy, more like an unusable, chaotic heap of bricks, slates, window frames, and pipes, than something out of which we can build a habitable house. What confronts us is an immense pile of specialized jargon-ridden disciplines pursuing specialized intellectual problems dissociated from our problems of living, there being little indication as to how the non-specialist is to find his way through all this to discover and achieve what is of most value in life. Scientific, academic inquiry is not pursued, understood, taught, or organized in accordance with the over-all assumption that what ultimately matters is personal and social wisdom. 
In so far as a basic organizing assumption is built into present-day scientific, academic inquiry, it is that the aim of such inquiry is to improve objective, impersonal, institutional knowledge, not personal and social wisdom. Intellectual priority is not given to our problems of living, to the difficulties, frustrations, sufferings that we encounter in our lives in attempting to discover and achieve what is of value in life: on the contrary, intellectual priority is given to impersonal problems of knowledge encountered by the various academic disciplines in seeking to describe, predict, and explain phenomena. Even the social sciences give intellectual priority to problems of knowledge as they arise within sociology, psychology, and so on, rather than to the problems encountered by people in their lives. Intellectual progress is assessed, not in terms of the success we meet with in achieving what is of value in life, but rather in terms of the success achieved in acquiring academic knowledge. Intellectual progress is conceived as being decisively dissociated from human, social progress.

Impersonal, academic problems of knowledge may of course be tackled out of a concern to develop knowledge which can subsequently be used or applied to help solve human, social problems. The allimportant point, however, is that these problems of knowledge are neither understood nor tackled as intellectually subordinate to our more fundamental problems of living, but are, on the contrary, decisively dissociated from these. If science is to be of human value, it tends to be argued, it is essential that science acquires reliable, objective, impersonal factual knowledge, this in turn requiring - so the argument goes - that the problems of knowledge be tackled in a way which is decisively dissociated from the problems of life.

From the standpoint of developing a kind of intellectual inquiry designed to help us achieve what is of value in life, however, all this is irrational in a quite elementary fashion, and for precisely the reasons emphasized throughout this paper. Granted that the fundamental task of intellectual inquiry is to help us solve those personal, social problems of living we encounter in seeking to achieve what is of value in life, elementary rules of rational problem-solving require us to give intellectual priority to the task of articulating these personal, social problems of living, and proposing and criticizing possible (and actual) solutions to them. Rationality also requires, of course, that we develop a multitude of subordinate, specialized problems - for example, technological problems, scientific problems, problems of knowledge and understanding. It is absolutely essential for rationality, however, that these specialized problems are understood as subordinate, the enterprise of tackling them being set within the framework of the more fundamental intellectual activity of proposing and criticizing possible solutions to our problems of living.

The philosophy of knowledge is, as I have said, at present almost universally taken for granted by the academic community, and is built into the whole institutional structure of the scientific, academic enterprise. As a result, the elementary irrationality of this philosophy has damaging repercussions for the whole of intellectual inquiry, and indeed for the whole modern world, all our lives here on earth. Both 'applied' and 'pure' intellectual inquiry, it should be noted, are damaged by the general acceptance of the philosophy of knowledge.

On the one hand we may - with Bacon, Comte, Bernal, and Ravetz, for example - be concerned primarily with the capacity of intellectual inquiry to help us solve our practical social problems. If so, then according to the philosophy of wisdom, intellectual priority needs to be given to articulating these problems, and proposing and criticizing possible solutions. Solutions to practical social problems are appropriate personal, social actions. Hence, according to the philosophy of wisdom, the fundamental intellectual task of intellectual inquiry is to develop imaginatively and assess critically possible and actual personal, social actions. The development of knowledge and technology needs to be rationally subordinated to the more fundamental intellectual activity of proposing and criticizing social actions.

The philosophy of knowledge, however, gives intellectual priority to the development of knowledge divorced from a concern with our social problems. New knowledge leads to the development of new technology which is then applied in ways which help, we may hope, to solve these problems. The crucial point, however, is that intellectual priority is given to the task of proposing and criticizing claims to knowledge - laws, theories, experimental results - instead of possible social actions.

Inevitably, as a direct result of giving intellectual priority to the development of knowledge rather than to proposing and criticizing possible solutions to social problems, intellectual inquiry must: (1) fail to help us solve all those major social problems which require new social actions, policies, and institutions for their resolution rather than new knowledge and technology; (2) fail to help us give priority to the development of new knowledge and technology most needed for the resolution of urgent social problems; (3) fail to help us use such knowledge and technology, where developed, to maximum advantage in a rational fashion to help solve social problems; (4) fail to help us anticipate and prevent 
new knowledge and technology being used in socially harmful ways; (5) fail to help us anticipate and refrain from engaging in intrinsically harmful scientific research; (6) fail to concentrate intellectual attention on our most urgent social problems. ${ }^{59}$ These six kinds of failure are all immediate consequences of the fundamental failure to give intellectual priority to rational human, social problemsolving. As long as our thinking about the world and ourselves is dominated by the philosophy of knowledge, it is almost inevitable that the social ills of the modern world will arise, even if almost everyone acts with good will.

On the other hand we may - with Kepler, Spinoza, Einstein, and Popper, for example - be concerned primarily with the 'intrinsic' or cultural value of intellectual inquiry, intellectual inquiry pursued for its own sake. If so, then we need to recognize - as emphasized by the philosophy of wisdom - that it is knowledge and understanding achieved by people that ultimately matters. 'Pure' intellectual inquiry, conceived of in impersonal or institutional terms, is of value in so far as it helps us to achieve that which really has value - our personal knowledge and understanding of our world, our personal curiosity, perceptiveness, capacity to discover that which is of significance in our surroundings, and the extent to which all this enriches our life. The problems of 'pure' intellectual inquiry are, in other words, at the most fundamental level, personal and interpersonal problems, problems that we encounter in seeking to enhance our personal knowledge and understanding of the world, our personal perception and appreciation of what is significant and of value in existence. As Einstein once remarked: 'Knowledge exists in two forms -lifeless, stored in books, and alive in the consciousness of men. The second form of existence is after all the essential one; the first, indispensable as it may be, occupies only an inferior position..$^{60}$ To this I would only add that from the standpoint of 'pure' intellectual inquiry it is perhaps the activity, as a part of life, of imaginatively exploring the world, following up our passionate curiosity, the lively encountering of aspects of reality, that is the thing that is essentially of value. And just as the professional, specialized, institutionalized activities associated with music are designed, ideally, to further our making and enjoying of music, so too the professional, specialized, institutionalized activities associated with science are, ideally, designed to further our exploration and enjoyment of our world.

All this is in marked contrast with the views of those who, like Popper and Ziman, emphasize the fundamental importance of 'objective knowledge', of 'knowledge without a knowing subject', of 'public knowledge', or of 'institutional knowledge', conceived as ends in themselves, rather than as means to the achievement of the end of life of value, via enhancement of personal awareness of the world. ${ }^{61}$ In insisting that 'pure' science be dissociated from life, intellectual progress being understood in wholly objective, impersonal, or institutional terms, the philosophy of knowledge misses out precisely that which matters most, our personal apprehension of the world. As a result of putting this philosophy of impersonal knowledge into practice, a disastrous split develops between the way we personally apprehend or conceive of the world, and the way 'science' apprehends or conceives of the world. We fail to exploit science in order to enrich and extend our personal vision of things; and we fail to develop science in such a way that it is amenable to such exploitation. We fail to discover how to use scientific theories as spectacles through which we may, conjecturally, view the world. Instead of emphasizing the priority of the personal problems of understanding we need to solve in order to make such a use of scientific theories, the problems are dismissed as 'subjective', the development of impersonal knowledge embodied in scientific theories becoming an end in itself. As a result we become blind to - or ignore - the profound discrepancies that exist between the world as conceived by us in life, and the world as conceived, impersonally, by science. A kind of advanced intellectual schizophrenia in our thinking develops. Theoretical physics, for example, ceases to be, with Einstein, a personal 'attempt conceptually to grasp reality as it is thought independently of its being observed', ${ }^{62}$ and becomes merely the impersonal, institutional, ritualistic prediction of phenomena, 'the whole thing . . . a wretched bungle ...' which can 'only claim the interest of shopkeepers and engineers'." Personal awareness of what is significant and of value in existence, intellectual passion, curiosity, wonder, all degenerate into nothing more than the possession of information and expert skills, the accumulation of dry knowledge of fact. As a result of dissociating 'pure' intellectual inquiry from life, we lose sight of the value which intellectual inquiry has when pursued for its own sake.

Above all. and quite generally, as a result of engaging in, and thinking in terms of, intellectual inquiry as in the first instance the pursuit of impersonal knowledge we lose sight of those problems which, quite fundamentally, create the need for intellectual inquiry, and which intellectual inquiry ought fundamentally to be helping us to solve. By giving priority to the pursuit of impersonal knowledge, we fail to emphasize the fundamental character of the personal and social problems of our pluralistic world. 
Intellectual inquiry must then fail to enhance our common understanding of these problems and our common capacity to develop more adequate resolutions to them. Conceiving of things in terms of the pursuit of impersonal knowledge, we fail entirely to see the urgent need to develop intellectual inquiry as the fundamentalist tribal discussion of humanity, as a vital part of all our lives, as a personal and social reality, as a part of the world, designed to help us create wiser ways of living, wiser institutions, a wiser world.

Whereas the philosophy of wisdom, in short, in subordinating intellectual inquiry to the needs of life of value, does justice to both the pragmatic and the cultural aspects of intellectual inquiry, in a unified way ${ }^{64}$ the philosophy of knowledge fails to do justice to both aspects.

Specialism is a relatively recent phenomenon, a general intellectual malaise that has progressively overtaken scientific, academic inquiry during the last hundred years, and especially during the last fifty years. The natural philosophers of the seventeenth century, the philosophes of the eighteenth century, and many scientists, philosophers, and social thinkers of the nineteenth century had no difficulty in conceiving and pursuing intellectual inquiry in broadly fundamentalist terms (even if epistemological and methodological misconceptions prevented them from having a full understanding of the rationale for fundamentalism indicated here).

I have argued in this last section that there is nevertheless an even deeper intellectual and humanitarian malaise inherent in scientific, academic inquiry, which cannot by any means be construed as a relatively recent phenomenon. On the contrary, it goes back to the origins of modern science some four hundred years ago and can even be traced back to the ancient Greeks of over 2,000 years ago. It is built into the very foundations of the Western tradition. It can be put like this. Intellectual inquiry has been pursued in accordance, not with the philosophy of wisdom, but rather with the philosophy of knowledge. Instead of problems (3) and (4) of Section II being taken as fundamental, problems (I) and (2) being tackled as an aspect of, and subordinate to, problems (3) and (4), on the contrary scientific, academic inquiry has been devoted primarily to solving problems (1) and (2), solutions to aspects of these problems incidentally helping people in social life to develop improved answers to problems (3) and (4) (or so it is hoped). Instead of problems (3) and (4) being held to constitute the central problems of intellectual inquiry, on the contrary these problems have been ostracized from rational inquiry, relegated to the domain of the personal and the political, solutions to them being determined by such 'irrational' factors as subjective emotion and motivation, political power, market forces.

But if present-day scientific, academic inquiry really is damagingly irrational in the quite elementary and fundamental way indicated, it may be asked: How is it possible? How can such a wholesale, fundamental irrationality have been tolerated for so long? It is not difficult to understand why in the seventeenth century questions concerning the value of life should not have been open to rational discussion: the combined power of church and state made it impossible. (One only has to remember the difficulties encountered by Galileo, Descartes, and others in seeking to establish the principle that relatively neutral problems concerning the nature of the material universe should be open to non-authoritarian, rational discussion to realize that any attempt to establish an analogous principle in connection with problems concerning the meaning and value of life was, at the time, out of the question.) The philosopher of the eighteenth century sought to devote reason to the enhancement of human enlightenment, human progress; unfortunately, and understandably, being overimpressed by Bacon and Newton, they failed to emphasize, clearly and unambiguously, that intellectual priority needs to be given to wisdom rather than to knowledge. Romantic writers of the late eighteenth and nineteenth centuries can be interpreted as emphasizing the priority of questions concerning life of value. Unfortunately, in doing so, they abandoned 'reason' under the mistaken impression that reason is relevant only for the acquisition of impersonal knowledge of truth, and that it involves the repression of personal feelings, desires, and imagination. The question we need to ask is this: Why have these past failures not been put right in the twentieth century? A major part of the answer is, I suggest, the increasing prevalence of specialism, which has cancelled the very possibility of critical, influential discussion of fundamentals. Indeed, the existing fundamental disorganization of contemporary scientific, academic inquiry, with its elevation of knowledge above wisdom, is just what one would expect from putting specialism into practice - as the house analogy indicates. Indeed the pursuit of knowledge dissociated from the pursuit of wisdom is itself the outcome of a kind of specialism - the tackling of impersonal, objective, or institutional problems of knowledge dissociated from those more fundamental personal and interpersonal problems that face us in our search for what is, or can be, of value in 
existence. This elementary irrationality inherent in our official, public thinking about the world and ourselves is at the root of our present failure, as indicated by Higgins and others, to tackle our fundamental problems effectively and humanely. It is this that is responsible for the 'glaring contrast' noticed by Martin Luther King.

\section{NOTES}

1 These fundamental problems may of course be formulated a little differently from this without affecting the over-all argument. I shall argue, in fact, that these problems need to be understood, at the most fundamental level, as personal and interpersonal, or social, problems which we encounter in our lives. The exact form in which problem (3), for example, arises for any individual will depend upon the circumstances in which the individual finds himself. 'How can I get enough to eat?', 'How can I find worthwhile, productive work to engage in?', 'How can I give and receive love?', 'How can my life be of value if 1 am to grow old and die?", 'What am I to do with my life?', 'How can I develop my present pursuits so that 1 achieve more successfully that which is of real value?' These can all be regarded as possible variants of problem (3).

2 '... the one method of all rational discussion ... is that of stating one's problem clearly and of examining its various proposed solutions critically.' (K. Popper, The Logic of Scientific Discover,-. Hutchinson, London 1956, p. 16.)

3 We may, e.g.. regard a problem as having the form of an aim we seek to realize and some provisional idea for a route to the realization of our aim, which fails, however, to enable us to achieve the aim. As a result of representing problems in this fashion, we may well adopt the idea that rationality involves quite essentially seeking to improve our aims and methods as we act by imaginatively developing and critically scrutinizing possible and actual aims and methods. For an exposition of this somewhat more sophisticated 'aim oriented' conception of rationality -and its implications for intellectual inquiry- see N. Maxwell. The Rationality of Scientific Discovery: Part II; An Aim Oriented Theory of Scientific Discovery', Philosophy of Science, Vol. 41 (1974), pp. 247-95; and What's Wrong with Science ${ }^{I}$ ?, Brans Head Books, Middlesex 1976, esp. Ch. 9.

4 See P. Gay, The Enlightenment: An Interpretation: 1, The Rise of Modern Paganism, Wildhood House, London 1973, pp. 3-19, 127-203.

5 I am grateful to L. Briskman for provoking me into discussing this objection explicitly.

$6 \mathrm{I}$ even put this forward as a psycho-neurological hypothesis: our wonderful unconscious problem-solving capacity, which we exhibit so effortlessly in life whenever we perceive, understand, speak and act, is due to the fact that a fundamentalist hierarchical structure is programmed, as it were, into the neurological structure of our brains. This has evolved as a result of natural selection (problem-solving ability - and above all the ability to solve relevant problems [procured by the fundamentalist hierarchical structure] - having great survival value). Unfortunately, at present, nothing like so intelligent a structure is built into scientific, academic inquiry - or into much conscious thought - in that here, lamentably, specialism prevails. In particular we have failed to build the hierarchical structure of fundamentalism into our civilization. Not surprisingly, this civilization, or world order, at present exhibits a terrifying failure to recognize and resolve its fundamental problems problems most relevant to the achievement of what is of most value-even to the extent that its very survival is now in doubt.

7 K. R. Popper, The Open Society and its Enemies (1945), Routledge \& Kegan Paul, London 1966.

8 Some modem writers have done full justice to the great potential value of living and working in a small community or 'tribe': see, e.g., C. Turnbull, The Forest People, Picador, London 1976; E. F. Schumacher, Small is Beautiful: A Study of Economics as if People Muttered, Blond \& Briggs. London 1973, and 'A Blueprint for Survival', The Ecologist, Vol. 2, No. 1 (Jan. 1972). Popper's failure to recognize this potential must be due partly to his being unacquainted with the anthropological evidence. He asserts that 'the main element' of the tribal 'magical attitude towards social custom' is 'the lack of distinction between the customary or conventional regularities of social life and the regularities found in "nature" '.this often being associated with 'the belief that both are enforced by a supernatural will'. Social customs are rigidly maintained, there being a superstitious fear of change, magical 'taboos rigidly regulating] and dominating] all aspects of life'. Significantly, Popper adds that 'comparatively infrequent changes have the character of religious conversions or convulsions, or of the introduction of new magical taboos'. (See The Open Society and it.** Enemies, op.cit.. Vol. I, p. 172.) It is striking that Turnbull finds all these Popperian characteristics of tribal life dominating 
the life of agricultural Bantu tribes in central Africa. Turnbull describes just such a rigid, tabooridden, superstitious, compulsive, fearful, ritualistic way of life. Turnbull's really-remarkable discovery. however, is that all this is entirely absent in the Pygmy hunting and gathering tribal way of life. The Pygmies' lives are imbued with a quite extraordinary spontaneity, grace, and trust, there being a complete absence of superstition, compulsive ritual, or fearful observance of taboo. Turnbull argues, in my view entirely convincingly, that it is the development of agriculture which is responsible for this dramatic difference in the whole way of life. Hunting and gathering tribes can afford to live spontaneously, from day to day. trusting in the forest to provide food for tomorrow. Agricultural tribes, on the contrary, live in a state of constant battle with the environment and must perform persistent, long-term agricultural work before food and reward are eventually forthcoming. (M. Harris, in Cannibals and Kings, Fontana, London 1978, comes to the conclusion, from a consideration of archaeological evidence, that early hunting and gathering tribes 'enjoyed relatively high standards of comfort and security", having more leisure than later agricultural tribes.) Thus, it is not closeness to Nature, but the exact opposite, departure from dayto-day dependency on Nature, the development of agricultural technology, which creates rigidity, taboo, and ritual. In any case, the Pygmies decisively refute Popper's contention that tribal life is invariably rigid, ritualistic, and irrational. In many ways, in fact, our modern 'open' societies in the industrially advanced West are closer, at the institutional level, to the Bantu reliance on rigidly maintained ritual and taboo, than to the Pygmy reliance on spontaneous instinct and skill. And-of particular relevance to the theme of this essay - this is perhaps especially true of modern specialized scientific, academic research. Rigidly maintained taboo and ritual, broken only by 'comparatively infrequent changes' having 'the character of religious conversions or convulsions' this corresponds almost exactly to specialist scientific research as described and documented by Kuhn in his The Structure of Scientific Revolution* (Chicago University Press, Chicago 1970). Even the vocabulary is the same. Kuhn describes scientific revolutions as infrequent episodes of crisis, inducing intense anxiety while they last, the process of acquiring the new paradigm constituting a kind of irrational religious conversion.

At present one perhaps needs the serene self-assurance and lucidity of an Einstein (acquired as a result of sustained, instinctive fundamentalist thought) to recapture the spontaneity and trust of the Pygmy way of life in the modern scientific world. It is clear that in Einstein's case scientific curiosity arose spontaneously from the heart in response to a feeling of 'rapturous amazement at the harmony of natural law'. (In a letter to Gertrud Warschauer in 1952 Einstein wrote: 'You have given me great joy with the little book . about Faraday. This man loved mysterious Nature as a lover loves his distant beloved. In his day there did not yet exist the dull specialization that stares with self-conceit through hornrimmed glasses and destroys poetry. ...') And Einstein found no difficulty in conceiving himself as a part of Nature. When asked to respond to the question 'If, on your death bed, you looked back on your life, by what facts would you determine whether it was a success or failure?', Einstein replied: 'Neither on my death bed nor before will I ask myself such a question. Nature is not an engineer or contractor, and I myself am a part of Nature.'

9 From B. Hoffmann. Albert Einstein: Creator and Rebel, Hart-Davis, MacGibbon, London 1973. p. vii.

10 The destructive impact of industrially more advanced ways of life on primitive or so-called primitive ways of life has been, and is at present, all too often, blatant and brutal. But it can also be subtle and unintended. For a perceptive account of this in connection with the importation of Western economic ideas and practices, see Schumacher, 5m«///A Beautiful, op. cit.

11 Einstein was always aware of the instinctively fundamentalist character of childish thinking - as well as of the childish origins of mature fundamentalist thought - associated, for him, essentially with curiosity provoked by a sense of wonder, together with scepticism concerning the received dogmas of the adult world. In explanation of his own fundamentalist thinking concerning the structure of the physical universe he once remarked that ordinarily only children take such problems seriously. He, however, - a late developer - continued to pursue such elementary questions; and, as an adult, naturally, was better equipped to come up with improved answers. On another occasion he remarked: 'There exists a passion for comprehension, just as there exists a passion for music. That passion is rather common in children, but gets lost in most people later on. Without this passion, there would be neither mathematics nor natural science.' (A. Einstein, Ideas and Opinion*. Souvenir Press, London 1973, p. 342.) And in connection with 
his own education, in a well known passage, he remarks: 'In this field ... [of physics] I soon learned to scent out that which was able to lead to fundamentals and to turn aside from everything else, from the multitude of things which clutter up the mind and divert it from the essential. The hitch in this was, of course, the fact that one had to cram all this stuff into one's mind for the examinations, whether one liked it or not. This coercion had such a deterring effect [upon me] that, after I had passed the final examination. I found the consideration of any scientific problems distasteful to me for an entire year. Injustice I must add, moreover, that in Switzerland we had to suffer far less under such coercion, which smothers every truly scientific impulse, than is the case in many another locality. There were altogether only two examinations; aside from these, one could just about do as one pleased. This was especially the case if one had a friend, as did I, who attended the lectures regularly and who worked over their content conscientiously. This gave one freedom in the choice of pursuits until a few months before the examination, a freedom which I enjoyed to a great extent having gladly taken into the bargain the bad conscience connected with it as by far the lesser evil. It is, in fact, nothing short of a miracle that the modern methods of instruction have not yet entirely strangled the holy curiosity of inquiry; for this delicate little plant, aside from stimulation, stands mainly in need of freedom; without this it goes to wrack and ruin without fail. It is a very grave mistake to think that the enjoyment of seeing and searching can be promoted by means of coercion and a sense of duty'. (A. Einstein, 'Autobiographical Notes', in P. A. Schilpp [Ed.], Albert Einstein: PhilosopherScientist. Open Court, La Salle 1945 [1970], p. 17.)

12 See T. S. Kuhn, The Structure of Scientific Revolutions, op. cit., Ch. IV.

$13 \mathrm{Kuhn}$, e.g., argues that the instigation of the specialized, autonomous puzzle-solving of the specialist is essential for scientific progress. Ibid., pp. 21, 24, 37, and 64-65.

14 As we shall see below, there is a further vital point of difference. Fundamentalism asserts that inquiry can only be really intellectually rigorous if it is recognized that inquiry (thought, problem-solving), at the most fundamental level, goes on in life as an integral part of our personal and social lives, actively helping us to discover and achieve what is of most value in life, potentially and actually, as we live.

15 A further clarification to be elaborated below. Fundamentalism conceives of intellectual progress, fundamentally, in personal and social terms, in terms of progress in our achievement of what is of value in life, in terms of the progress in our personal and social thinking actively associated with and guiding our endeavours to achieve what is of value, on a personal and world-wide basis.

16 A remark about the first and last of these 'fundamentalists'. Einstein once said: 'I want to know how God created this world. I'm not interested in this-or-that phenomenon, the spectrum of thisor-that element. I want to know His thoughts, the rest are details.' (See E. Salaman, 'Memories of Einstein', Encounter. April, 1979, p. 22.) In The Seventh Enemy: The Human Factor in the Global Crisis (Hodder \& Stoughton, London 1978) R. Higgins outlines with devastating clarity and force six basic threats to the future of civilization-six fundamental world-wide problems which we must somehow resolve on a world-wide basis if mankind is to survive. His 'seventh enemy' is our human incapacity to acknowledge and respond to these fundamental problems, on both individual and social, political or institutional, levels. Thus, on a world-wide-basis, life on earth is at present almost lunatically irrational in the most elementary fashion (since it fails to put into practice the two most elementary rules of rational problem-solving).

17 See D. de S. Price. Science since Babylon, Yale University Press. New Haven 1961. It must be emphasized that this modern meaning of the phrase, introduced by Price, is a typical specialist perversion of the original fundamentalist meaning intended, e.g., by Boyle in the seventeenth century when he writes: The "Invisible College" consists of persons that endeavour to put narrow-mindedness out of countenance by the practice of so ex tensive a charity that it reaches unto every thing called man, and nothing less than an universal good-will can content it. And indeed they are so apprehensive of the want of good employment that they take the whole body of mankind for their care. But. . . there is not enough of them.' (Quoted in G. Werskey, The Visible College, Alien Lane, London 1978, p. 13.)

18 It is noteworthy, e.g.. that Higgins (The Seventh Enemy, op. cit.) is obliged to break all conventional academic boundaries in order to articulate our basic global problems. It is also noteworthy that these problems discussed by Higgins and others do not receive sustained, 
influential discussion as an integral part of the orthodox scientific, academic enterprise.

19 I refer here, of course, to the dominant schools of philosophy in Britain and the USA since the war, ordinary-language philosophy, conceptual analysis, logical empiricism, and descriptive metaphysics, as practised by, e.g., Ryle, Austin, Ayer, Anscombe, Warnock, Hare, Kenny. Strawson. Carnap, Hempel. Quine, Davidson, and many others. Recently there have been indications of some improvement in this tradition. Thus Mary Midgley's recent book Breast and Man: The Roots of Human Nature (Harvester Press, Sussex 1979) can be interpreted as making a valuable contribution to the fundamental problem: How do we fit into the world and how have we come to be? Unfortunately, Midgley takes for granted the conceptual analyst's conception of philosophy, and a form of specialism for intellectual inquiry as a whole.

In contrast to this tradition there are, e.g., Marxist philosophy and existentialism. Unfortunately, Marxist philosophers are more or less committed to interpreting philosophy as conscious or unconscious ideology - Marxist philosophy, in particular, thus being the detailed, specialized development and application of Marxist social theory and ideology - an attempt, by intellectual means, to help humanity realize Marxist social and political objectives, prejudged to be desirable. As a result, Marxist philosophers fail to practise fundamentalism, which involves, amongst other things, the conscious articulation and criticism of ideologies, social theories, social and political programmes interpreted as possible solutions to our fundamental problems. (Unlike Higgins, Marxists do not begin with problems, but rather with a basic, presupposed solution. As a result, radical critics of the Marxist solution cannot be valued by Marxists as colleagues concerned to help solve essentially the same problems, but must inevitably be judged to be ideological and political opponents. The cooperative, rational development and appraisal of alternative possible solutions to our problems - including Marxist solutions - thus becomes impossible.)

Existentialism, on the other hand, can be interpreted as insisting that our most fundamental problems are problems we encounter in our lives - problems of living. If so. then the version of fundamentalism advocated in Sect. VII amounts to a kind of thoroughgoing, radical, rationalist existentialism. Three features of this version of fundamentalism. in marked contrast to some features of traditional existentialism, must nevertheless be stressed. (1) All scientific. academic problems are to be interpreted as rational!) subordinate to our problems of living, as we live. (This stands in marked contrast to some strands of existentialism, to be found in Kierkegaard and Dostoevsky for example, which are romantic, anti-scientific, and anti-rationalist in character.) (2) Our fundamental problems of living are interpersonal, or social, in character, as well as personal or individualistic. (Again, this is in marked contrast to the exclusively individualistic emphasis to be found in the existentialist writings of Kierkegaard and Dostoevsky.) (3) Rational problemsolving quite generally-and thus rational personal, social problem-solving in particular-involves quite essentially retaining a record of past successes and failures. Rational problem-solving is essentially accumulative and progressive in character. (This is in marked contrast to Sartre's hysterical repudiation of the past. Enhancing our freedom, our capacity to discover and achieve what is of value in life, requires that we learn from the successes and failures of the past, our personal and social history. The Sartrian repudiation of the past, in order to achieve freedom, in fact enslaves us to compulsive acting out of impulse.)

20 Something like this account is presupposed, or propounded, by: G. Ryle. 'Introduction' in A. J. Ayer et al.. The Revolution in Philosophy, Macmillan. London 1967. pp. 1-11; A. J. Ayer, Metaphysics and Common Sense. Macmillan. London 1969, Ch. 1. 'On Making Philosophy Intelligible', pp. 1-18: C. H. Whiteley. An Introduction to Metaphysics, Methuen, London 1955. pp. 5-6.

21 An amusing indication of this is the way in which philosophers tend to acknowledge, apologetically or critically, that philosophy still concerns itself with the problems discussed by. e.g.. Plato, whereas other disciplines successfully solve initial problems and move on to new problems, thus making progress. The failure of philosophy to progress in this way is only problematic if philosophy is conceived in specialist terms. From the standpoint of the fundamentalist or Enlightenment conception of philosophy, it is of course precisely the basic task of philosophy to keep alive, throughout the whole of intellectual inquiry, and throughout our culture and social life, a sustained concern with our four fundamental problems.

22 For a more detailed and sophisticated advocacy of this fundamentalist conception of science, see my 'A Critique of Popper's Views on Scientific Method', Philosophy of Science. Vol. 39 
(1972), pp. 131-52; 'The Rationality of Scientific Discovery', op. cit., Vol. 41 (1974), pp. 123-53, 247-95; 'Articulating the Aims of Science', Nature. Vol. 265 (1977), p. 2; 'Induction, Simplicity and Scientific Progress', Scientia, 1980 (forthcoming); What's Wrong with Science?, op. cit.; 'How Science Lost its Humanity', The Guardian, 27 Sept. 1979, p. 19. For a critical assessment, see G. F. Kneller, Science as a Human Endeavor. Columbia University Press. New York 1978. pp. 3638. 80-37, 90-91.

23 See B. Russell. Human Knowledge: Its Scope and Limits. Alien \& Unwin. London 1948. (Contrast Russell's uncritical or inflexible 'postulational' approach with the critical, flexible postulationism of aim-oriented empiricism [see Note 22], which stresses that science, in order to be rational, must continuously articulate, develop and criticize metaphysical blueprints for science as an integral pan of scientific inquiry, and in the light of ostensible scientific progress, thus enabling us to improve our aims and methods as our scientific knowledge and understanding of the world improves.)

24 K. Popper, The Logic of Scientific Discovery, op. cit., pp. 19, 38, 277-8.

25 K. Popper, Unended Quest: An Intellectual Autobiography, Fontana/Collins, Glasgow 1976, pp. $148-51$.

26 K. Popper. Conjecture* and Refutations, Routledge \& Kegan Paul, London 1963, pp. 193-200.

27 Ibid., pp. 66-67.

28 K. Popper. The Logic of Scientific Discovery, op. cit., p. 15; Conjectures and Refutations, op. cit., p. 136.

29 Ibid., pp. 67-\%, 136.

30 See I. Lakatos and A. Musgrave (Eds.), Criticism and the Growth of Knowledge, Cambridge University Press, London 1970, p. 53.

31 K. Popper, 'Reason or Revolution?', in The Positivist Dispute in German Sociology, Heinemann Educational Books Ltd., London 1976, p. 296.

32 K. Popper, Conjectures and Refutations, op. cit., p. 54.

33 See Note 22.

34 This important point can be established quite simply as follows. Science is centrally concerned to solve the problem: What kind of world is this? If science is to tackle this problem rationally, priority needs to be given to proposing and critically assessing possible solutions - thus developing a tradition of rational cosmology like that represented, e.g.. by Popper in his 'Back to the Presocratics' (Conjectures and Refutations, op. cit.. Ch. 5). This leads, however, to the development of a number of rival imprecise possible solutions - rival cosmologies - with no indication as to how we are to make these vague ideas precise and choose between them. In order to proceed, we need to put into practice the third and fourth rules of rational problem-solving: each vague solution needs to generate preliminary, subordinate, specialized problem-solving. If one such approach begins to achieve apparent spectacular specialized success, then this entitles us to take this general approach especially seriously. Thus the spectacular specialized successes of Kepler and Galileo entitle us to take especially seriously their common vague cosmological presupposition: 'the book of Nature is written in the language of [simple] mathematics.' If science is to proceed rationally, however, it is essential that there continues to be an (interplay between our best ideas as to how the over-all problem is to be solved, and our best solutions to subordinate problems. In particular, our assessment of possible solutions to subordinate problems - testable scientific laws and theories - must not be dissociated from our assessment of untestable, metaphysical ideas as to how the over-all problem is to be solved. Popper, however, violates this elementary, general requirement for rationality in insisting that assessment of scientific laws and theories ;'.v dissociated from assessment of metaphysical ideas. Furthermore, it is precisely this irrational insistence which creates, for Popper, the insoluble problem of induction. The impossibility of assessing scientific laws and theories solely with respect to empirical success is a special case of the general irrationality of attempting to assess possible solutions to subordinate problems independently of vague ideas about how to solve the over-all problem. The problem of induction, in short, is a product of specialism, the insolubility of the problem, as traditionally conceived, an indication of the irrationality of specialism as far as science is concerned.

35 Ironically enough, Popper does come close to acknowledging the Russellian point that the methods of science make implicit metaphysical presuppositions about the nature of the world (see The Logic of Scientific Discovery, op. cit., pp. 252-4), despite explicit disavowals elsewhere (see 
Conjectures and Refutations, op. cit., p. 54). He fails, however, to emphasize that critical rationalism requires that we explicitly articulate these metaphysical presuppositions, so that they may be criticized, and thus, we may hope, improved, as an integral part of science, so that the methods of science maybe improved with our improving knowledge. Just this way of doing science was instigated by Einstein in developing the special and general theories of relativity. The invariance and symmetry principles of modern physics - which can be interpreted as either methodological or metaphysical principles - are a development of Einstein's profound innovation. However, modern physics, and modern science quite generally, fail to put into practice, explicitly and fully, Einstein's way of doing science, in that they fail to articulate and criticize actual and possible aims and methods-or philosophies of science-as an integral pan of science itself. The institutional reorganization that this requires - namely philosophy of science pursued as an integral part of science itself- has not been carried out. This is of course in part due to the fact that the scientific community accepts Popper's falsificationist demarcation criterion for dividing off science from non-science. Views about what ought to be the aims and methods of science - philosophies of science - not being themselves testable theories in any straightforward sense, have no place in science itself according to traditional, and Popperian, empiricism. Thus scientific integrity at present demands that discussion of aims and methods be excluded from science, instead of demanding that this discussion constitute an integral part of science (as required by aim-oriented empiricism or fundamentalism). At present, by and large, science departments and departments of history and philosophy of science do not speak to each other. To this extent. Popper, rather than Einstein, is institutionalized. This institutionalization of Popperian methodology prevents us from developing a genuinely rational, fundamentalist science.

36 For Einstein's advocacy of fundamentalism see. e.g.. A. Einstein. Ideas and Opinions, op. cit. 37 See Note 13.

38 See T. S. Kuhn, The Structure of Scientific Revolutions, op. cit.. Ch. 12.

39 It should be noted that the basic objection to Kuhn's prescription for science applies with almost equal force to Lakatos's prescription as outlined in his 'Falsification and the Methodology of Scientific Research Programmes', in I. Lakatos and A. Musgrave(Eds.|, Criticism and the Growth of Knowledge, op. cit.. pp. 91-195. Lakatos's problem is to reconcile the dogmatism of Kuhn's normal science, on the one hand, with the anti-dogmatic, critical falsificationism of Popper, on the other hand, taking into account especially Feyerabend's important point that in order to test a given theory severely we need to possess, and even develop, alternative theories. (See P. Feyerabend. 'Problems of Empiricism ${ }^{1}$, in R. G. Colodny [Ed.]. Beyond the Edge of Certainly. Prentice-Hall, Englewood Cliffs, N.J. 1965, pp. 145-260.) Lakatos's solution is to prescribe for science simultaneous competing fragments of Kuhnian normal science - competing research programmes - thus doing justice simultaneously to Kuhnian dogmatism and Feyerabendian pluralism. Lakatos makes it abundantly clear, however, that ultimately only relative empirical success ought to decide the fate of research programmes within science. There is thus no essential role, within Lakatos's conception of science, for sustained critical development of our best metaphysical answer to the problem. What kind of world is this?, so that the hard cores of research programmes could be assessed in part in terms of this answer. Lakatos advocates a kind of competitive specialism. In terms of our obstacle-course analogy, Lakatos sees science as a number of competing individuals, with different routes in mind, stumbling blindly from $A$ to $B$.

40 A number of writers (e.g. Koyre. Burn, and Buchdahl) have advocated a view which might be called 'metaphysical presuppositionism', according to which the natural sciences do make substantial metaphysical presuppositions about the world. These writers fail, however, to emphasize the crucial point that scientific rationality demands sustained, explicit, critical development of such metaphysical presuppositions as an integral pan of science itself- the essential tenet of fundamentalism.

41 For a powerful criticism of the idea that the social sciences should be value-neutral, see B. Easlea, Liberation and the Aims of Science: An Essay on Obstacles to the Building of a Beautiful World. Chatto \& Windus, London 1973, pp. 167-78. Essentially the same point is made by Schumacher in his Small is Beautiful, op. cit., when he argues that economic thinking must reflect or presuppose some philosophy of life, some view as to what is of 
value in life. For the point that explicit articulation and criticism of value assumptions implicit in the aims of research is actually essential for the whole of science if it is to be objective and rational, see N. Maxwell, 'Science and Values', Times Higher Educational Supplement. 4 Nov. 1977, p. 27; What's Wrong With. Science", op. cit., Chs. 5 and 7. Values are even implicit, it should be noted, in the aims of a science as apparently remote from ordinary life as pure theoretical physics. The question. What kind of world is this?, may be interpreted in such a fashion that merely developing theories, like quantu m theory, which predict more and more phenomena more and more accurately constitutes satisfactory progress towards answering the question. Einstein asked for much more from theoretical physics: he sought to capture, in a 'wildly speculative way' the 'thoughts of God". He did not know that the universe has a coherent, unified structure: rather, the mere possibility of discovering such a structure seemed to him to be of such supreme value that to abandon the search for it seemed to be a profound betrayal of the noblest aspirations of theoretical physics. Thus Einstein's judgment that quantum theory is unsatisfactory, in that it abandons micro-realism, was in part based on a value judgment. (For an endorsement of Einstein's judgment on this point see my Towards a Micro-Realistic Version of Quantum Mechanics', Foundations of Physics, Vol. 6 [19761, pp. 275-92, 661-76.1

42 R. K. Merton. Science. Technology and Society in Seventeenth-Century England. Harper \& Row. New York 1970: K. Mannheim, Essays in the Sociology of Knowledge, Routledge \& Kegan Paul. London 1952; W. O. Hagstrom, The Scientific Community, Basic Books. New York 1965; B. Homes, Scientific Knowledge and Sociological Theory, Routledge \& Kegan Paul. London 1974; P. Mathias (Ed.). Science and Society 1600-1900. Cambridge University Press, London 1972; M. Teich and R. M. Young (Eds.), Changing Perspectives in the History of Science, Heinemann, London 1973; M. Mulkay, Science and the Sociology of Knowledge, George Alien \& Unwin, London 1979.

43 On the one hand there are those who pursue sociology of science and 'externalist' history of science merely in order to add to specialist knowledge within sociology and history. These writers tend to decry the significance of epistemology and the study of scientific method. (A notable recent example of this is to be found in D. Bloor, Knowledge and Social Imagery. Routledge \& Kegan Paul, London 1976.) From the standpoint of the fundamentalist viewpoint defended in Sect. VII, this approach entirely misses the point. For, according to the view advocated below, the basic task of the social sciences is to help us develop more rational institutions and ways of life, a more rational world. A central task of the social sciences, in other words, is to propose and critically assess possible institutional and social changes designed to help people all the better to discover and achieve what is of value in life - that is, to help people solve rationally the problems of living which they encounter in seeking to achieve that which is of value in life. The social sciences, on this view . ought thus fundamentally to be institutional or social epistemology or methodology. What is being attempted in this paper in connection with one institution -the scientific, academic enterprise - should be attempted quite generally in connection with institutions associated with politics, the law, the media, commerce, industry, and international relations Far from the sociology of science taking over from the philosophy of science socio!ogy on the contrary - and the social sciences quite generally - need to become the philosophy and methodology of institutional, social pursuits and enterprises. Granted that our concern is to develop better solutions to problems (3) and (4), a central task of the social sciences and humanities ought to be to help us develop fundamentalist, or aim-oriented rationalistic, institutions quite generally - including aim-oriented rationalistic academic institutions. See What's Wrong With Science.', op. cit., Chs. 8 and 9.

On the other hand, however, there are those Marxist-inclined writers who wish to commit science to socialist or Marxist objectives and who seek to 'radicalize' science. (See. e.g., B. Easlea, Liberation and the Aims of Science, op. cit.; H. Rose and S. Rose [Eds.], The Radicalization of Science. Macmillan, London 1976.) These writers see social and cultural reality in terms of competing class interests - the dominant class ensuring that even culture and science serve its own class interests, this situation being maintained, in part, by means of the 
institutionalized lie that science is an objective, value-neutral search for truth, serving no special class interests. There is clearly some truth in this allegation. The moment we view scientific and technological research on a worldwide basis, it becomes clear that very little such research is devoted to serving the interests of the millions upon millions of desperately poor people in the third world. In so far as such research does serve social interests, it is the interests of those who live in industrially advanced, relatively wealthy countries which are served-even to the point of increasing the misery of the underprivileged, as in the case, perhaps, of the tin miners of Bolivia. The fundamental defect of this Marxist conception of intellectual inquiry, however, is that it commits intellectual inquiry to socialist or Marxist social theory and objectives, and thu s prevents intellectual inquiry from itself scrutinizing these social, political and evaluative presuppositions, even to the point of improving on them.

We might view the matter as follows. (1) Standard empiricists, like Hempel and Popper, reject the existence of permanent metaphysical presuppositions inherent in science. (Even Kuhn and Lakatos only allow for temporary metaphysical presuppositions to be assessed ultimately in terms of the empirical success of the specialist research they support; thus Kuhn and Lakatos ultimately also advocate standard empiricism.) This is dishonest, as the insolubility of the problem of induction indicates. (2) Metaphysical presuppositionists. like Russell. Koyre. Bum, and Buchdahl, do acknowledge the existence of long-term, comprehensive metaphysical presuppositions implicit in science. This is more honest. These writers fail, however, to emphasize the crucial importance of articulating and critically developing such presuppositions as an integral part of science. In addition these writers fail to acknowledge the existence of valuepresuppositions implicit in science. This is dishonest. (3) Easlea, Schumacher. and others do acknowledge the existence of such value-presuppositions implicit in science. This is more honest still. These writers fail, however, to emphasize the crucial import ance of articulating and critically developing such presuppositions as an integral part of intellectual inquiry-thus failing to advocate a rational, fundamentalist version of the philosophy of wisdom. In addition, merely to acknowledge that value-presuppositions are implicit in intellectual inquiry is to fail to acknowledge that intellectual inquiry is itself a part of personal, social life, a kind of personal, social action, pursued in order to realize personal, social goals. This is dishonest. (4) Radical Marxists go further, in that they do conceive of, and pursue, intellectual inquiry as an aspect of personal, social action, designed to help achieve personal, social objectives. According to these writers, in capitalist societies intellectual inquiry is devoted primarily to helping to attain the objectives of capitalism: in their intellectual work these writers seek to act in such a way as to help overthrow capitalism, thus creating a socialist society and a socialist intellectual inquiry devoted to helping to realize socialist goals. In so far as these writers see and pursue intellectual inquiry as an aspect of life, social reality, social action, their vision and practice is even more honest still. These writers fail, however, to acknowledge the crucial importance of articulating and critically developing basic socialist presuppositions and objectives. They fail to confront obvious major problems inherent in the idea of a socialist society - such as the problem of centralized, bureaucratic power. This is dangerously dishonest. In particular, as a result of this failing, these writers fail to emphasize the fundamental importance of seeking to develop ways of life, institutions, societies, which progressively develop the aims and methods of personal, institutional and social life - thus enhancing our capacity to achieve that which is of value in life. These writers presuppose answers to problems (3) and (4), instead of seeking to develop a fundamentalist, rational society which enables us to discover improved answers to these problems, as we live.

In short, despite their diversity, the four positions just outlined have one crucial failing in common: they all fail to emphasize that rational action involves quite essentially seeking to improve our aims and methods as we act - the key tenet of aim-oriented rationality (see my What's Wrong With Science'.', op. cit.).

44 A. Huxley, Means and Ends: An Enquiry into the Nature of Ideals and into the Methods employed for their Realization, Chatto \& Windus, London 1938, pp. 276-7.

45 For a fascinating account of such a hunting and gathering tribal life, see C. Turnbull. op. cit.

46 Higgins writes (op. cit., pp. 21-45) especially clearly and convincingly on this point, in part from personal experience.

47 A humane, cooperative, mutually understanding, pluralistic society presupposes and is, in a 
sense, presupposed by, fundamentalism. If two people, two societies, or two cultures, giving different answers to our four fundamental problems, are to act humanely and cooperatively together, there must be mutual understanding; this requires that each is able to imagine, at least as a possibility, that the other's answers are correct (oral least an improvement, in certain respects, over his own). This in turn requires that each recognizes the genuineness of the four fundamental problems. If each is to learn from the other, then each must acknowledge the genuineness of the four fundamental problems. On the other hand, to recognize that these problems are genuine is to imagine at least the possibility of answers different from one's own being given - which is to imagine a pluralistic society, at least as a possibility.

Only fundamentalism can do justice to the Socratic and Kantian idea that Reason forms a basis for the unity of mankind.

48 M. Mead, Coming of Age in Samoa: a Study of Adolescence and Sex in Primitive Societies. Penguin Books Ltd., Harmondsworth 1943.

49 'Reason, like language, can be said to be a product of social life.' (K. Popper, The Open Society and its Enemies, op. cit., Vol. 2, p. 225.) See also the discussion of the claim that science is necessarily social in character. "Robinson Crusoe science', however successful, being necessarily only 'revealed science' in that it must lack objectivity, pluralistic criticism (ibid., pp. 216-20). Unfortunately, Popper in his later work fails lamentably to develop these anticipations of the point stressed in this paper (see, e.g.. Note 47), that reason, epistemology, thought, intellectual inquiry, all need to be conceived of, and developed, as personal and social in character, in the world, a part of life.

If we adopt the view advocated in Sect. VII that the aim of intellectual inquiry is to help us achieve wisdom, life of value, then the fundamental aim of intellectual inquiry becomes a personal, social aim, and the problems of intellectual inquiry become, fundamentally, personal, social problems of living. Our central task, in pursuing intellectual inquiry, becomes to help develop more rational, wiser ways of living, institutions, social orders. The split between personal, social aims and intellectual aims-the split between personal, social action and thought - disappears. Popper, however, holds that the basic aim of intellectual inquiry is to develop impersonal, objective knowledge. This leads him to develop his 'world 3' theory of the intellectual domain. As a result, and quite disastrously, the fundamental personal and social problems of intellectual inquiry problems we encounter in helping to develop life of value, a wiser world - are transformed into the pseudo metaphysical-neurological problems of how 'world 3' can interact with the mind and the brain. See K. Popper, Objective Knowledge, Oxford University Press, London 1972; K. Popper and J. Eccles, The Self and Its Brain, Springer-Verlag, London 1977.

Fundamentalism, in sharp disagreement with Popper, recognizes just one world. Within fundamentalism, Popper's conceptually incoherent psycho-neurological thesis that world 3 interacts with world 1 via world 2 can be replaced by the kind of conceptually coherent psychoneurological postulate indicated in Note 6 , or by a version of this postulate which asserts that aimoriented rationalism is programmed into the neurological structure of our brains-or at least needs to be so 'programmed' if we are to be able to achieve what is of value in life. (For an exposition of aim-oriented rationalism see What's Wrong With Science?', op. cit., esp. Chs. 8 and 9.) There is only one world; it is in this world that fundamentalism and aim-oriented rationalism need to flourish. In order to help achieve this, it is essential that we see fundamentalist intellectual standards, aim-oriented rationality, as something embedded, actually and potentially, in this world. It is essentially this insight that we need to see implicit in much of Popper's The Open Society and its Enemies in order to appreciate the real value of that work, and in order to make sense of Popper's wonderful suggestion that we should see intellectual evolution as a development of biological evolution. In the circumstances it is somewhat tragic that Popper should have gone on, with the development of his three-world view, to reject explicitly the insight that reason needs to be seen as materially and socially embodied in this one world. 50 According to Popper, we must learn to live with the intense emotional strain of civilization, as the price that must be paid for reason, for the open society, for civilization. Any attempt to introduce social and cultural changes which alleviate this strain must be fiercely resisted, as such changes must inevitably lead to totalitarianism. However, as indicated in Sect. II, this is because Popper fails to conceive of the possibility of fundamentalism, and is led as a result to defend a seriously irrational and undesirable conception of rational inquiry and civilization. 
For purposes of clarification, I should indicate four further main differences between the viewpoint being advocated in this essay, and views advocated or presupposed in Popper's writings. The chief difference, unquestionably, is simply this. I advocate that the basic aim of rational inquiry is to enhance wisdom. Here I part company not only with Popper, but with the whole Western tradition, in that this tradition gives to rational inquiry the basic aim of enhancing knowledge (human welfare, enlightenment, and progress being only secondary and uncertain byproducts of the basic and prior achievement of knowledge). As a result of giving priority to wisdom - to our living, actual capacity to discover and achieve what is of value in life - I am led to locate rational inquiry, at the most fundamental level, within and amidst our lives, personal and interpersonal or social. This leads me to stress the fundamental importance of aim-oriented rationalism designed to help us improve our aims, and thus our lives, as we live (aim-oriented empiricism being simply a special case of aim-oriented rationalism, applicable to science). This is in marked contrast to Popper's conception of reason, which he has called critical rationalism (falsificationism being simply, for Popper, a special case of critical rationalism, applicable to science). Since for me rational inquiry has, as its basic task, to help us achieve what is of value in life, I hold that all intellectual values need ultimately to be founded in human value - especially in the supreme value of each individual person, and the good things that can go on between people once this is recognized - rigorous, objective inquiry being, as though by definition, a universal tool perfectly designed to help us all maximally to achieve, or grow, life of value. I thus disagree absolutely with Popper's thesis - in effect a standard component of the philosophy of knowledge that purely scientific values should be distinguished as sharply as possible from human or extra-scientific values. (This is Popper's sixteenth thesis in his 'The Logic of the Social Sciences', in The Positivist Dispute in German Sociology, op. cit., pp. 96-98.) The purpose of the present essay is to argue that the rationality, the intellectual rigour, the objectivity, of inquiry is essentially bound up with the capacity of inquiry to help us resolve those problems of living we need to resolve in order to achieve what is of value in life. That which is of value in life is primary: intellectual value is a reflection of- or is subservient to - primary value in life. Ideas - including the idea of this essay are spectacles intended to help us to see clearly what is of value in existence, actually and potentially; they are forks and spades designed to help us to cultivate what is of value in our lives, in reality. Like spectacles, ideas are to be assessed in terms of whether they serve to clarify or blur our vision; like forks and spades, ideas are to be assessed in terms of their use, their success in practice. The idea that intellectual value is dissociated from value in life, in the world, quite fundamentally misconceives the proper value and use of ideas: pushed to the extreme this becomes Plato's doctrine of the forms. (The Popperian, Western doctrine of the autonomy of intellectual value devolves, in fact, from Plato's doctrine.) The idea that intellectual value needs to be conceived of as dissociated from value in the world - and not as integral to and contributing to value in the world - receives support no doubt from the desire of many intellectuals to find in intellectual work some kind of escape from the world, a quiet and transparent refuge.

Given Popper's defence of the orthodox doctrine concerning the autonomy of purely scientific or intellectual value, it is not at all surprising that he should call Hume's thesis that 'Reason is, and ought only to be, the slave of the passions' a 'horrifying doctrine' ( $\mathrm{K}$. Popper, 'How I see Philosophy', in A. Mercier et at. [Eds.], Philosophers on their Own Work, Vol. 3, Peter Lang, Las Vegas 1977, p. 132). An upholder of aim-oriented rationalism and the philosophy of wisdom would wish to make only minor adjustments to Hume's thesis. Either reason should be held to be the slave of that most profound passion of ours of all to participate in life of value: or reason ought perhaps to be called the 'good servant' or 'enlightened tutor' of the passions - reason itself the outcome of our cooperative, balancing, or resolving passion for a whole, authentic life of value. As a result of conceiving of inquiry and reason as being an essential, active component of human life, more or less realized in practice in our personal and social actions, I am led to avoid the conceptual incoherence of Popper's three-world view, as indicated in Notes 6 and 49.

In general, the viewpoint that I wish to advocate is much closer to Einstein's than to Popper's, taking into account especially the emphasis that Einstein came to place in his later life on the fundamental importance of developing a living ethical culture, and a kind of education designed to help us acquire and participate in such a culture. 'It is not enough 
to teach a man a speciality. Through it he may become a kind of useful machine but not a harmoniously developed personality. It is essential that the student acquire an understanding of and a lively feeling for values. He must acquire a vivid sense of the beautiful and of the morally good. Otherwise he - with his specialized knowledge - more closely resembles a well-trained dog than a harmoniously developed person. He must learn to understand the motives of human beings, their illusions, and their sufferings in order to acquire a proper relationship to individual fellow-men and to the community.' (A.

Einstein, 'Education for Independent Thought', in Ideas and Opinions, op. cit., p. 66.)

51 See Isaac Bashevis Singer, The Manor (1975), The Estate (1975), The Seance and Other Stories (1977), A Friend of Kafka (1975), A Crown of Feathers and Other Stories (1977), Enemies: A Love Story (1977), all published by Penguin Books Ltd., Harmondsworth.

52 E. Fromm, The Fear of Freedom, Routledge \& Kegan Paul, London 1960. See also, for example, his The Sane Society, Routledge \& Kegan Paul, London 1963.

53 P. Gay.The Enlightenment: An Interpretation: I, The Rise of Modern Paganism, op. cit., PP. 59-71.

54 In R. Colodny (Ed.), Beyond the Edge of Certainty, op. cit., pp. 145-260.

$55 \mathrm{It}$ is doubtless commitment to this kind of oracular conception of reason which leads both Kuhn and Feyerabend, in their rather different ways, to characterize science as irrational. The same mistake is implicit in almost all forms of relativism.

56 In this paper I am of course arguing that even though the goal is difficult to attain, nevertheless it is a matter of supreme importance that we seek to build fundamentalism, rather than specialism, into the institutional structure of the scientific, academic enterprise, and education. Indeed what I am proposing goes much further than this. We need to build fundamentalism, and aim-oriented rationalism, into our whole way of life, into society as a whole, into the human world. The basic aim of intellectual inquiry ought to be to devote reason to the enhancement of wisdom. This programme can scarcely begin to be put into practice, however, as long as specialism rather than fundamentalism is built into the institutional structure of the scientific, academic enterprise.

57 F. W. Haberman, Nobel Lecture*. Peace, 1951-1970, Vol. 3, Elsevier Publishing Co., Amsterdam 1972, pp. 333^1.

58 See J. Glenn Gray, The Promise of Wisdom, Harper \& Row, New York 1972. for the suggestion that the aim of education should be the achievement of wisdom in life. Gray fails to point out, however, that intellectual inquiry is at present profoundly irrational and defective when judged from the standpoint of having as its basic aim to help us achieve wisdom.

59 Only if intellectual priority is given to the task of proposing and criticizing possible and actual personal, social actions, policies, aims and methods, institutional enterprises, ideologies problems of knowledge and technology being tackled as subordinate to our fundamental personal, social problems of living-can intellectual inquiry overcome these defects. For an elaboration of this point see my The Rationality Scandal' (forthcoming).

60 A. Einstein, Ideas and Opinions, op. cit., p. 80.

61 K. Popper, Objective Knowledge, op. cit.; J. Ziman, Public Knowledge: The Social Dimension of Science, Cambridge University Press, London 1968.

62 P. A. Schilpp (Ed.), Albert Einstein: Philosopher-Scientist, op. cit., p. 80.

63 K. Przibram (Ed.), Letters on Wave Mechanics, Vision Press Ltd., London 1967, p. 39.

64 For a development of this point see my What's Wrong With Science?, op. cit., the subtitle of which reads: Towards a People's Rational Science of Delight and Compassion. 